\title{
Avaliação de Juntas Soldadas de um Aço Fundido de Alta Resistência para a Indústria Offshore
}

\author{
Olavo Ribeiro dos Santos Filho ${ }^{1}$, Jorge Luiz Coutinho Diniz ${ }^{1}$, Manoel José da Silva Coêlho ${ }^{1}$, Luis Felipe Guimarães de Souza ${ }^{1}$, \\ Jorge Carlos Ferreira Jorge ${ }^{1}$, Matheus Campolina Mendes ${ }^{1}$, Leonardo Sales Araújo² \\ 1 Centro Federal de Educação Tecnológica Celso Suckow da Fonseca - CEFET/RJ, Departamento de Engenharia Mecânica, \\ Rio de Janeiro, RJ, Brasil. \\ 2 Universidade Federal do Rio de Janeiro - UFRJ, Instituto Alberto Luiz Coimbra de Pós-graduação e Pesquisa de Engenharia - \\ COPPE, Rio de Janeiro, RJ, Brasil.
}

Recebido: 26 Abr., 2018

Aceito: 05 Jun., 2018

E-mails: jorgecfjorge@gmail.com (JCFJ)
Resumo: Os torpedos de ancoragem são estruturas tubulares de aço carbono soldadas, e que tem sua ligação com as linhas de ancoragem que impedem o movimento das plataformas através de olhais de carregamento que são soldados nos tubos de construção. Como estes olhais apresentam geometria complexa, é importante a utilização de peças fundidas para a fabricação destes componentes, de forma a possibilitar o atendimento da demanda do mercado. Como a literatura técnica sobre este tipo de união soldada é ainda limitada, o presente trabalho estuda o comportamento de juntas soldadas de um aço fundido de alta resistência para utilização em olhais de torpedos de ancoragem de plataformas offshore. Para tanto, foram produzidas juntas soldadas com chanfro em K utilizando um aço de classificação ASTM A 148 Gr. 105-85 com resistência mecânica da ordem de 700 MPa, pelo processo eletrodo revestido, na posição plana, com preaquecimento de $200{ }^{\circ} \mathrm{C}$ e energia de soldagem média de $1,5 \mathrm{~kJ} / \mathrm{mm}$. Após a soldagem, foi realizado tratamento térmico pós-soldagem (TTPS) consistindo de aquecimento a $620^{\circ} \mathrm{C}$ por 1 hora com resfriamento ao ar. As propriedades foram avaliadas por ensaios de tração, dureza, impacto Charpy-V e metalográficos por microscopia óptica e eletrônica de varredura com utilização da técnica de EBSD (eléctron backscatering difraction), tanto na condição de como soldado quanto após TTPS. Os resultados revelaram que, embora as propriedades mecânicas obtidas na junta soldada atendam os requisitos para a aplicação em todas as condições de análise, recomenda-se a execução do TTPS para alívio das tensões residuais e promover um revenimento da martensita de alta dureza do último passe de soldagem. Adicionalmente, verificou-se ser possível obter propriedades similares as de juntas soldadas de aços laminados usualmente utilizados em componentes de ancoragem.

Palavras-chave: Aço fundido; Soldagem; Propriedades mecânicas.

\section{An Evaluation of the High Strength Cast Steel Welded Joints for Offshore Industry}

Abstract: Torpedo anchor piles are tubular carbon steel welded structures that are connected to the mooring lines, which prevent the oil platform from moving, through padeyes welded to the structural pipes. Due to the complex geometry of these padeyes, cast pieces are an important option in the manufacturing of these items, in order to meet market demand. Considering the limited availability of information about such type of welded junction in the technical literature, the present work studies the behavior of welded joints of a high strength cast steel used on offshore platforms torpedo anchor padeyes. Thus, K-type joints were used for the welding of an ASTM A 148 Gr. 105-85 steel with an ultimate tensile strength of about $700 \mathrm{MPa}$, by using shielded metal arc welding process, in flat position, with a preheating of $200{ }^{\circ} \mathrm{C}$ and an average welding energy of $1.5 \mathrm{~kJ} / \mathrm{mm}$. After welding, a post weld heat treatment (PWHT) was applied, at $620^{\circ} \mathrm{C}$ for 1 hour, followed by air cooling. The properties were evaluated through tensile, hardness and Charpy-V impact tests, as well as metallographic examination by optical and scanning electron microscopy with the use of EBSD (electron backscatter diffraction) technique, in both as welded and after PWHT conditions. The results shown that, although the mechanical properties obtained for the welded joint achieved the requirements for the application in all analyzed conditions, the execution of PWHT is recommended for the relief of residual stresses and promotion of a tempering of the high hardness martensite of the last welding pass. Additionally, it was verified that it is possible to obtain properties that are similar to those of welded joints of rolled steels, which are usually used on mooring components.

Key-words: Cast steel; Welding; Mechanical properties.
Este é um artigo publicado em acesso aberto (Open Access)
sob a licença Creative Commons Attribution Non-Commerci que permite uso, distribuição e reprodução em qualquer meio, sem restriçōes desde que sem fins comerciais e que trabalho original seja corretamente citado. 


\section{Introdução}

O aumento das atividades marítimas para exploração de petróleo, têm exigido maiores volumes de fornecimento de materiais de alta resistência para atendimento da demanda das necessidades de operações de exploração e produção de águas profundas. Nestes casos, como a aplicação de plataformas fixas está limitada a 450 metros de profundidade [1], a opção por plataformas semi-submersíveis é uma opção atrativa [1-4].

Para operação destas plataformas por longos períodos de tempo (em torno de 20 anos), os custos envolvidos na operação fazem com que a ancoragem seja realizada por sistemas compostos por âncoras, amarras e acessórios [4-7] conforme mostrado na Figura 1 [7], sendo que estas linhas de ancoragem e seus componentes tomam importância fundamental, no tocante à seleção e manutenção dos materiais envolvidos, uma vez que são importantes pontos de falha dos sistemas de ancoragem [8].

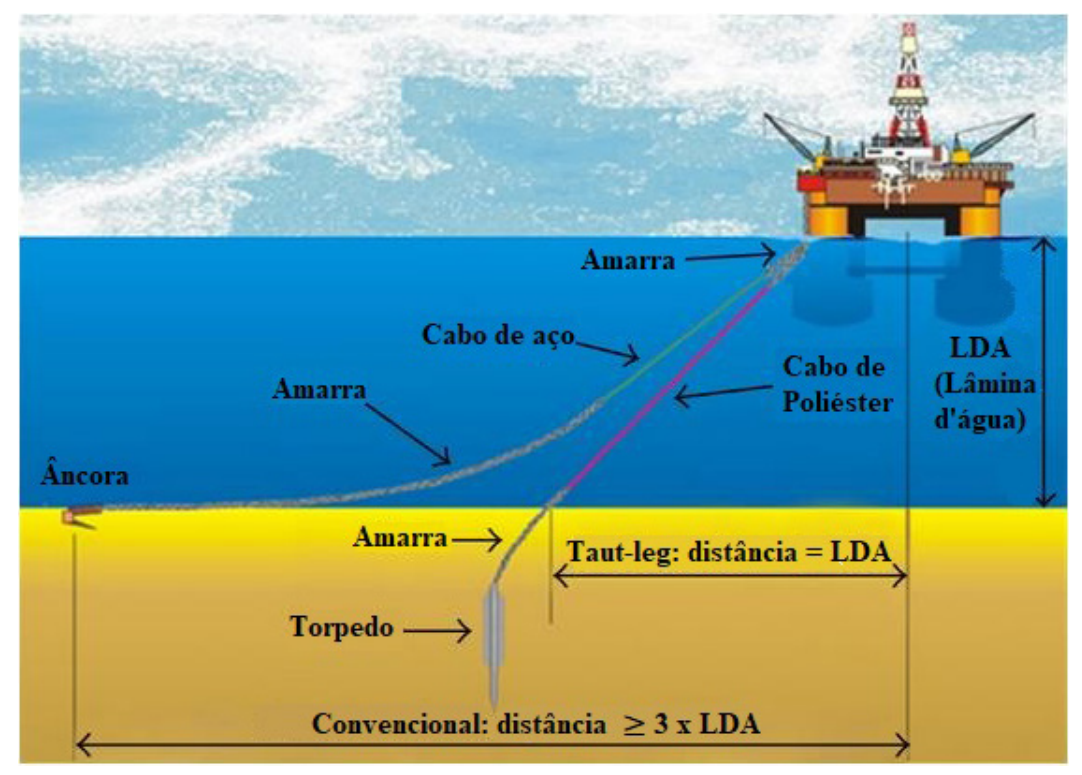

Figura 1. Características dos sistemas de ancoragem [7].

Neste aspecto, embora exista uma opção preferencial pelos materiais forjados em equipamentos de ligação devido ao melhor desempenho em fadiga [9], nem sempre é possível atender a esta opção, não somente por questões de fornecimento, como também por questões técnicas, devido a geometrias complexas dos componentes. De fato, alguns autores $[10,11]$ afirmam que existem componentes de linhas de ancoragem que apresentam projeto de difícil fabricação em aços forjados ou laminados com um preço e em prazo competitivo, tais como soquetes e manilhas de ancoragem (Figura 2).



Manilha de ancoragem para amarra (ref.10)

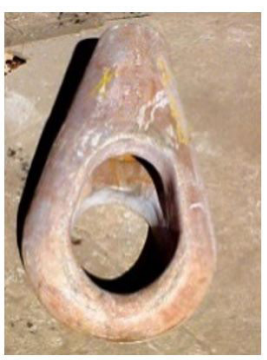

Soquete pera para cabo de aço (ref.10)

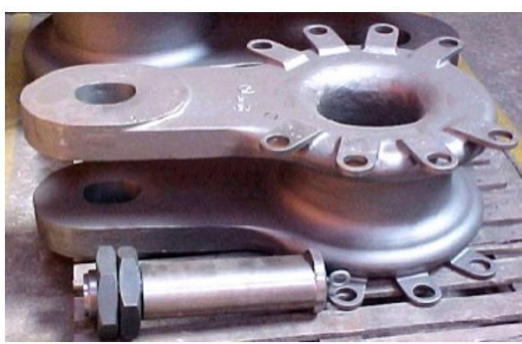

Manilha sapatilho para cabo de poliéster (ref.11)

Figura 2. Exemplos de acessórios fundidos [10,11]. 
Assim, os aços fundidos apresentam importância destacada na fabricação de equipamentos e componentes, tais como em peças de convés, cadastes e lemes, âncoras para navios e plataformas, amarras e acessórios para sistemas de amarração permanentes [9,10,12-17]. Embora, Bolouri et al. [18] comentem que a substituição de uniões soldadas por peças integralmente fundidas possa representar uma economia da ordem de $30 \%$ no custo de fabricação em unidades offshore, é de conhecimento geral que a elevada taxa de ocorrência de defeitos de fundição $[13,19]$ faz com que o reparo por soldagem seja um procedimento fundamental para evitar o sucateamento prematuro de equipamentos.

É importante mencionar que a preocupação sobre o desempenho de materiais fundidos com reparos por soldagem, pode estar associada ao pouco conhecimento sobre o assunto e com a verificação de que normas envolvendo os aços fundidos para fins estruturais [20] podem não apresentar requisitos rígidos de composição química, com consequências nas propriedades mecânicas e soldabilidade. Bolouri et al. [18] comentam que as informações sobre processamento de material, carbono equivalente e procedimentos de tratamentos térmicos adequados para atendimento dos requisitos de várias normas internacionais são ainda limitadas para os aços fundidos adequados para estruturas offshore. Isto torna a utilização de aços fundidos em acessórios de ancoragem um grande e inovador desafio, por ter que cumprir este requisito adicional, para o qual as fundições normalmente não estavam habituadas. No entanto, de forma a atender as demandas existentes na área offshore, as empresas de fundição desenvolveram aços especiais para algumas aplicações offshore com requisitos de tenacidade [12-19], fazendo com que a adoção de peças fundidas passasse a ser uma opção interessante. De uma maneira geral, o desenvolvimento dos materiais objetivou um balanço adequado de composição química para equilíbrio entre resistência, tenacidade e soldabilidade. De fato, a Tabela 1 mostra uma análise comparativa entre diversos aços fabricados por diferentes processos de fabricação [3,9,10,14,15,21-27], onde se nota que os aços fundidos apresentam uma vantagem comparativa em relação aos teores de carbono e/ou carbono equivalente, notadamente em relação aos aços forjados 4130 e 8630 usualmente utilizados na indústria offshore [9,26-32].

Tabela 1. Características de aços para aplicação offshore fabricados por diferentes rotas [9,10,14,15,21-27].

\begin{tabular}{ccccccccc}
\hline Processo & Aplicação & LR (MPa) & $\mathbf{C}$ & $\mathbf{M n}$ & $\mathbf{C r}$ & $\mathbf{N i}$ & Mo & Ceq(*) \\
Fundido [14] & Manilha & 704 & 0,24 & 1,37 & 0,45 & 0,69 & 0,32 & 0,63 \\
Fundido [15] & Manilha & 880 & 0,21 & 0,80 & 0,55 & 2,78 & 0,31 & 0,70 \\
Fundido [10] & Manilha & 915 & 0,19 & 0,78 & 0,64 & 2,58 & 0,33 & 0,69 \\
Laminado [21] & Elo de amarra & 686 & 0,29 & 1,79 & 0,15 & 0,03 & 0,04 & 0,63 \\
Laminado [22] & Elo de amarra & 716 & 0,31 & 1,60 & 0,04 & 0,01 & 0.07 & 0,59 \\
Laminado [23] & Elo de amarra & 715 & 0,31 & 1,60 & 0,17 & 0,13 & 0,02 & 0,63 \\
Laminado [24] & Elo de amarra & 891 & 0,22 & 1,12 & 1,07 & 0,70 & 0,22 & 0,70 \\
Laminado [25] & Elo de amarra & 884 & 0,23 & 1,50 & 1,00 & 0,60 & 0,40 & 0,80 \\
Forjado [26] & Conectores & 730 & 0,27 & 0,53 & 0,93 & 0,19 & 0,21 & 0,60 \\
Forjado [27] & Conectores & 754 & 0,31 & 0,92 & 0,97 & 0,88 & 0,42 & 0,81 \\
Forjado [9] & Manilha & 950 & 0,30 & 0,85 & 0,90 & 0,81 & 0,38 & 0,76 \\
\hline
\end{tabular}

$\left({ }^{*}\right) \mathrm{Ceq}=\mathrm{C}+\mathrm{Mn} / 6+(\mathrm{Cr}+\mathrm{Mo}+\mathrm{V}) / 5+(\mathrm{Ni}+\mathrm{Cu}) / 15$.

Além das situações usuais de reparo citadas anteriormente, podem existir aplicações onde o processo produtivo envolve necessariamente a avaliação do desempenho do material após o ciclo térmico de soldagem [12,13]. Este é o caso de torpedos de ancoragem (Figura 3), que representam uma solução efetiva para a ancoragem do tipo vertical ("taut-leg") de plataformas de petróleo (Figura 1). Neste tipo de ancoragem, o raio de ancoragem é menor do que o das linhas em ancoragem convencional do tipo catenária, o que permite a instalação de mais plataformas e diminui a possibilidade de interferência com outros sistemas ou com equipamentos submarinos [33], visto permitir uma redução significativa (cerca de 3vezes) do raio de ancoragem, associado com menor custo de instalação em comparação com âncoras convencionais [34].

Os torpedos de ancoragem são estruturas tubulares fabricadas em aço carbono com 20 metros de comprimento e peso da ordem de 120 toneladas, e que tem sua ligação com as linhas de ancoragem que impedem o movimento 




(a) Olhal fabricado em aço fundido

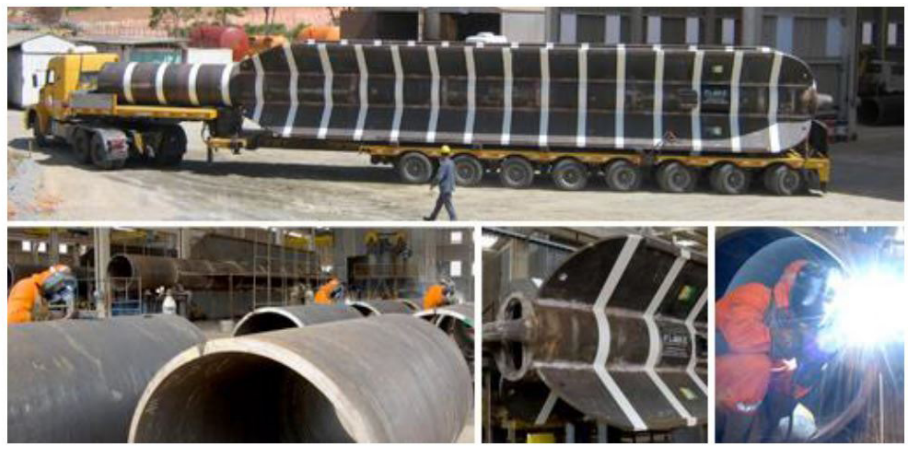

(b) Torpedo de ancoragem

Figura 3. Detalhes de olhal fundido utilizado em torpedos de ancoragem de 120 toneladas de peso [12].

das plataformas através de olhais de carregamento (Figura 3a), os quais são unidos aos tubos de construção através de soldagem (Figura 3b). Como estes olhais apresentam geometria complexa, utilizam-se peças fundidas para a fabricação deste componente para atendimento dos requisitos técnicos, de custo e de prazos de fornecimento.

Baseado neste cenário e considerando a limitada literatura técnica sobre o assunto, o presente trabalho tem por objetivo a avaliação das propriedades mecânicas de juntas soldadas de um aço fundido de alta resistência, de modo a permitir um melhor entendimento do comportamento destes aços para aplicação em componentes offshore.

\section{Materiais e Métodos}

\subsection{Materiais}

Como material base, foi utilizado um aço fundido de classificação ASTM A 148 Gr. 105-85 [20] na forma de bloco fundido com espessura de $47 \mathrm{~mm}$ e comprimento $400 \mathrm{~mm}$. O material recebido foi previamente normalizado, temperado e revenido a $640{ }^{\circ} \mathrm{C}$, apresentando a composição química e propriedades mecânicas mostradas nas Tabelas 2 e 3, respectivamente.

Tabela 2. Composição química dos materiais utilizados.

\begin{tabular}{ccccccccccc}
\hline Elemento(\% Peso) & C & Mn & Si & Cr & Ni & Mo & V & P & S & Ceq(*) \\
Metal base & 0,25 & 1,17 & 0,43 & 0,58 & 0,59 & 0,35 & 0,011 & 0,035 & 0,011 & 0,67 \\
Metal de solda & 0,07 & 1,46 & 0,45 & 0,85 & 2,22 & 0,65 & 0,02 & 0,010 & $<0,005$ & 0,76 \\
\hline
\end{tabular}

$(*) \mathrm{Ceq}=\mathrm{C}+\mathrm{Mn} / 6+(\mathrm{Cr}+\mathrm{Mo}+\mathrm{V}) / 5+(\mathrm{Cu}+\mathrm{Ni}) / 15$.

Tabela 3. Propriedades mecânicas do material base.

\begin{tabular}{cccccc}
\hline Propriedades & LE (MPa) & LR $(\mathbf{M P a})$ & Al(\%) & RA(\%) & Ecv (j) (-30 $\left.{ }^{\circ} \mathbf{C}\right)$ \\
Resultados & 645 & 766 & 21 & 44 & 83 \\
Mínimo [20] & 585 & 725 & 17 & 35 & $34\left({ }^{*}\right)$ \\
\hline
\end{tabular}

$\left({ }^{*}\right)$ Requisito adicional do projetista. Onde: $\mathrm{LE}$ = Limite de escoamento; $\mathrm{LR}$ = Limite de resistência; $\mathrm{Al}$ = Alongamento; RA = Redução de área; Ecv $=$ Energia absorvida no ensaio de impacto Charpy V.

Como consumível de soldagem, foram utilizados eletrodos revestidos de 4,0mm da classe AWS E12018M [35].

A Tabela 2 mostra a composição química realizada por espectroscopia de emissão ótica, tanto do metal base quanto do metal de solda da junta soldada estudada no presente trabalho. 


\subsection{Modelagem do olhal do torpedo}

Com o objetivo de avaliar o nível de tensões no olhal do torpedo (Figura 3a) em situações de operação, foi construído um modelo linear elástico isotrópico por elementos finitos.

A geometria foi dividida em elementos tetraédricos 3D, com razão de aspecto limitado em 3:1, sendo usados elementos de segunda ordem com 4 pontos gaussianos (Figura 4a). As condições de contorno envolveram restrições diretas na região do chanfro do olhal, de modo a simular as restrições de soldagem (Figura 4b). 0 carregamento considerou aplicação de força direta na região de carga (Figura 4c).

Foi utilizado o software comercial 3D "solid works" juntamente com o pacote de analise por elementos finitos ("simulation").

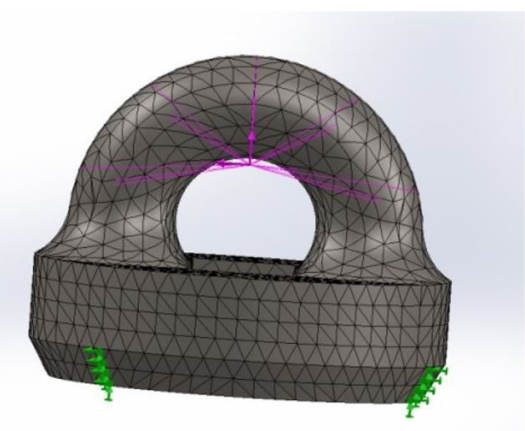

(a)

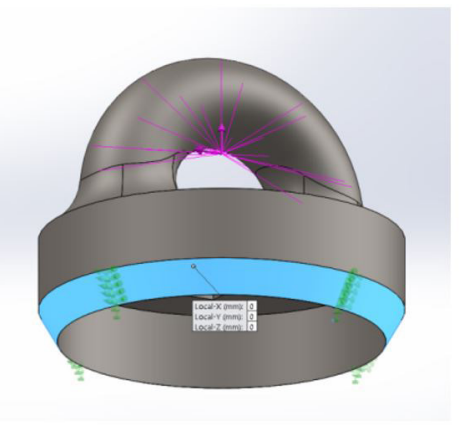

(b)

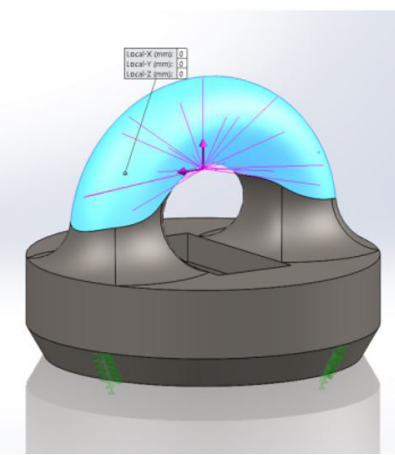

(c)

Figura 4. Condições de construção do modelo de elementos finitos. (a) Malha; (b) Condições de contorno; (c) Carregamento.

\subsection{Soldagem}

As juntas foram preparadas com chanfro em $\mathrm{K}$ com ângulo de abertura de $45^{\circ}$ e utilizou-se o processo eletrodo revestido com consumível da classe AWS E $12018 \mathrm{M}$ com 4,0mm de diâmetro. Realizou-se preaquecimento à temperatura de $200^{\circ} \mathrm{C}$ e posteriormente procedeu-se a soldagem multipasses, na posição plana, corrente contínua, eletrodo positivo, corrente média de $185 \mathrm{~A}$, tensão de $25 \mathrm{~V}$ e energia de soldagem de $1,5 \mathrm{~kJ} / \mathrm{mm}$ em 39 passes. A Figura 5 mostra a sequência de soldagem realizada, com destaque para a deposição de passes adicionais no lado B ("passe de revenimento"), de forma a permitir uma avaliação das propriedades mecânicas sem a execução de tratamento térmico pós-soldagem (TTPS).

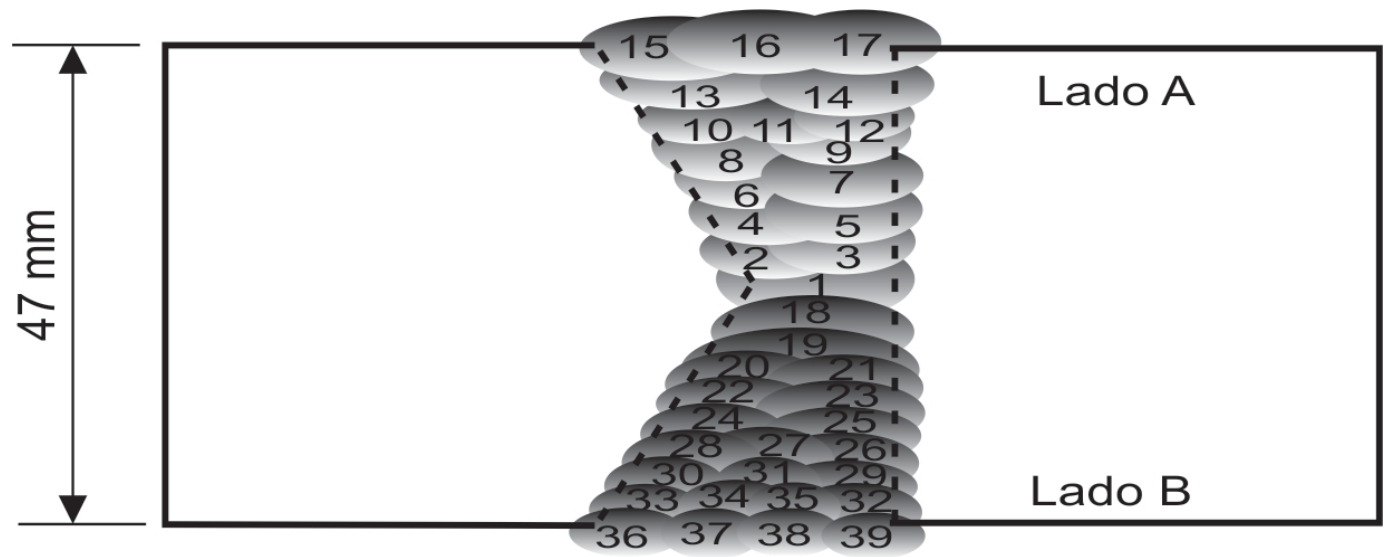

Figura 5. Geometria da junta e sequência de deposição. 
Após a soldagem, as juntas foram submetidas a inspeção não destrutiva por partículas magnéticas e ultra-som para avaliação de possíveis defeitos de soldagem.

\subsection{Tratamento Térmico Pós-soldagem (TTPS)}

As juntas soldadas foram testadas tanto na condição de como soldadas, quanto após realização de tratamento térmico (TTPS) consistindo de aquecimento à $620^{\circ} \mathrm{C}$ por 1 hora, seguido de resfriamento ao ar.

Os tratamentos térmicos foram realizados em forno, com aquecimento por resistência elétrica, isolamento com manta térmica e controle de temperatura através de termopares, devidamente calibrados. Utilizaram-se taxas de aquecimento e resfriamento controladas de $150^{\circ} \mathrm{C}$ por hora.

\subsection{Ensaios mecânicos}

Foram removidos corpos-de-prova transversais ao cordão de solda para ensaios de tração, impacto Charpy-V e dureza.

Foram realizados ensaios de tração à temperatura ambiente. Os ensaios foram realizados em corpos-de-prova com diâmetro 8,75 mm, normalizados conforme a norma ASTM A-370 [36] e retirados transversalmente ao cordão de solda, para avaliação da resistência mecânica da junta soldada, sendo realizados dois ensaios para cada condição analisada.

Foram realizados ensaios de impacto Charpy-V às temperaturas de -30 e $0^{\circ} \mathrm{C}$. Os ensaios foram realizados em corpos-de-prova normalizados conforme a norma ASTM A-370 [36] nas dimensões de $10 \mathrm{~mm}$ X $10 \mathrm{~mm}$ X $55 \mathrm{~mm}$, retirados transversalmente ao cordão de solda e a $3 \mathrm{~mm}$ da superfície da junta, sendo realizados três ensaios para cada condição analisada. $O$ entalhe foi posicionado no plano da espessura nas posições relativas ao centro do cordão de solda (MS), zona termicamente afetada (ZTA) a 1,0 mm da linha de fusão e metal base. A Figura 6 mostra a posição do entalhe Charpy-V para o metal de solda e a ZTA.
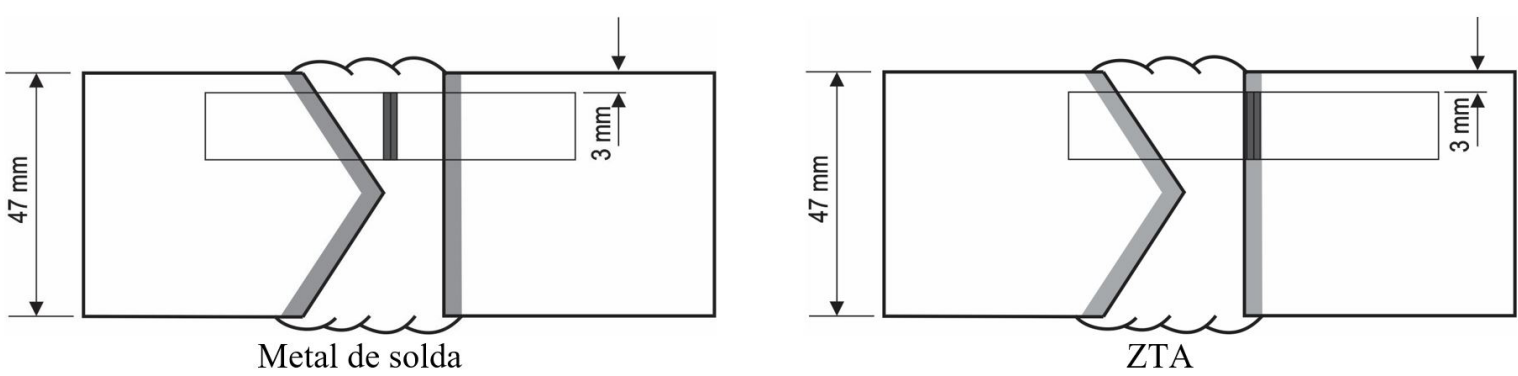

Figura 6. Posicionamento do entalhe Charpy-V nas juntas soldadas.

Foram realizados ensaios de microdureza Vickers de acordo com a norma ASTM A 370 [36], com aplicação de carga de 500 gf.em corpos-de-prova transversais ao cordão de solda, sendo realizadas medidas de microdureza em intervalos de 1,0 mm, na região do último passe e também na região correspondente ao centro do entalhe do corpo de prova de impacto Charpy-V, abrangendo o metal de solda, ZTA e metal base. Foram ainda realizados estes mesmos ensaios na ZTA, sendo realizada uma varredura de microdureza ao longo da espessura, na região correspondente ao entalhe do corpo-de-prova de impacto Charpy-V, para avaliar a variação de dureza ao longo da espessura nesta região da junta soldada. A Figura 7 ilustra o posicionamento dos ensaios de microdureza.

Todos os ensaios mecânicos foram realizados nas condições de como soldado e após tratamento térmico.

Para os ensaios de dureza e impacto Charpy-V, foram ainda removidos corpos de prova do lado B (Figura 5) da junta soldada para avaliação das propriedades após a realização do passe de revenimento (PR). 


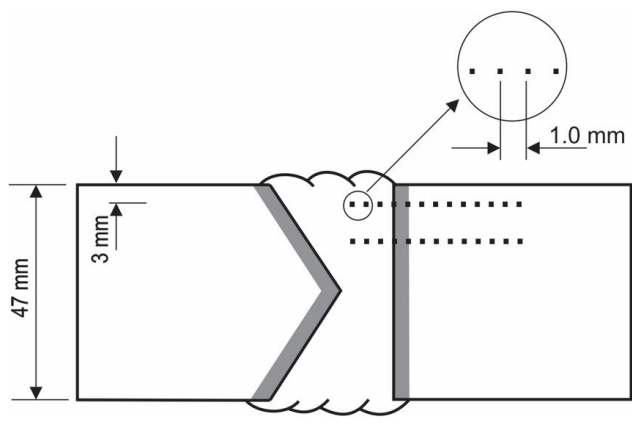

Medidas transversais nas diversas regiões das juntas

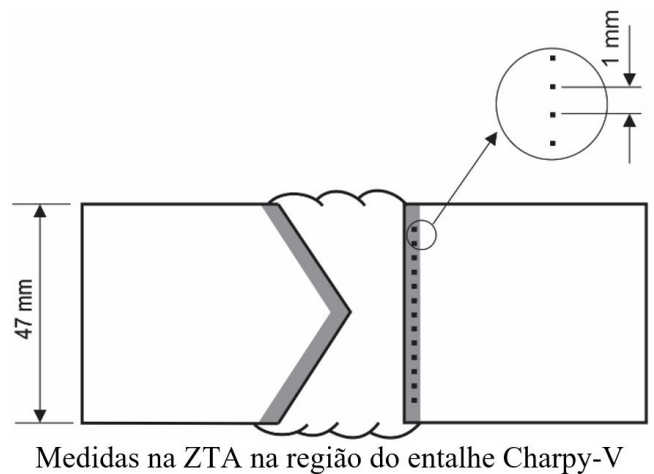

Medidas na ZTA na região do entalhe Charpy-V

Figura 7. Posicionamento dos ensaios de microdureza Vickers.

\subsection{Ensaios metalográficos}

Foram realizados ensaios macro e micrográficos por microscopia ótica (MO) e eletrônica de varredura (MEV) para avaliação das microestruturas das diversas regiões das juntas soldadas, tanto na condição de como soldado quanto após tratamento térmico.

Foi ainda realizada análise por EBSD (Eléctron Backscatering Difraction) da região de grãos grosseiros da ZTA na posição relativa ao centro do corpo de prova de impacto Charpy-V, utilizando o MEV com voltagem de 20KV, distância de trabalho de $20 \mathrm{~mm}$, ângulo de inclinação da amostra de $70^{\circ}$ e step-size de $0,3 \mu \mathrm{m}$.

O pós-processamento (reconstrução dos mapas) dos dados de EBSD foi realizado utilizando o software Channel 5. A orientação dos grãos foi realizada pela figura de polo invertida (FPI) na direção Z (direção transversal, perpendicular a tela). Contornos de grão de alto ângulo (ângulo de desorientação $>15^{\circ}$ ) foram distinguidos pela desorientação escalar entre os pixels adjacentes.

O preparo das amostras para análise consistiu do procedimento convencional de lixamento e polimento com pasta de diamante com granulometrias $6,3,1$ e $1 / 4 \mu \mathrm{m}$, seguido de ataque químico com o reagente nital $2 \%$.

Para análise por EBSD, realizou-se um polimento adicional com sílica coloidal com granulometria de $0,25 \mu \mathrm{m}$.

\subsection{Simulação termodinâmica}

De forma a verificar a formação de fases na ZTA, foram realizados cálculos termodinâmicos com o emprego do programa Thermocalc, versão 2017b, utilizando a base de dados termodinâmica para aços TCFE8. Para tal, estimativas das fases precipitadas durante a temperatura de revenido $\left(620^{\circ} \mathrm{C}\right)$ por meio de diagramas de fração em massa fases formadas versus temperatura foram calculadas, considerando a composição química do metal base.

\section{Resultados}

\subsection{Modelagem por elementos finitos}

A Figura 8 mostra os resultados obtidos na análise por elementos finitos para simulação do carregamento de operação do olhal quando da ancoragem da plataforma, onde se observa que os valores mais elevados de tensão ocorrem na região próxima ao chanfro, o que significa que a região crítica do olhal estará sendo afetada pelo ciclo térmico de soldagem.

\subsection{Ensaios de tração}

A Tabela 4 mostra os resultados dos ensaios de tração realizados nas diversas condições de análise, onde se verificam as seguintes características:

a) Todos os resultados obtidos de limite de escoamento e limite de resistência encontram-se superiores aos mínimos exigidos [20];

b)Todos os corpos-de-prova romperam no metal base e;

c) A execução do TTPS não promoveu mudanças significativas nos valores de resistência mecânica das juntas soldadas. 


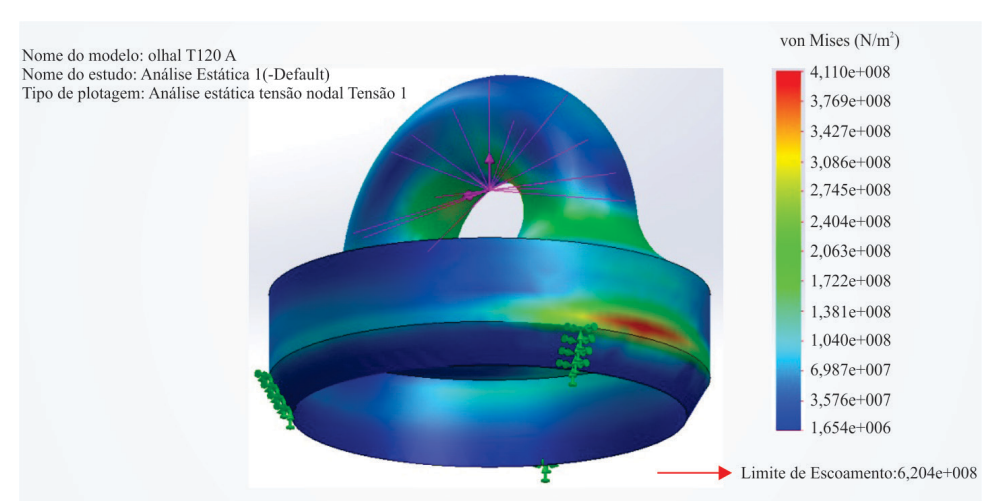

Figura 8. Resultados da análise por elementos finitos no olhal de ancoragem do torpedo.

Tabela 4. Resultados dos ensaios de tração.

\begin{tabular}{ccccc}
\hline Condição & CP & LE(MPa) & LR(MPa) & Posição da fratura \\
Como soldado & CP1 & 664 & 849 & Metal base \\
& CP2 & 642 & 776 & Metal base \\
& Média & 651 & 812 & - \\
TTPS & CP1 & 639 & 816 & Metal base \\
& CP2 & 614 & 765 & Metal base \\
& Média & 627 & 791 & - \\
\hline \multirow{2}{*}{ Mínimo [20] } & - & 585 & 725 & - \\
\hline
\end{tabular}

\subsection{Ensaios de impacto Charpy-V}

As Figuras 9 e 10 mostram os resultados dos ensaios de impacto realizados nas diversas condições de análise, onde se verificam as seguintes características:

a)Todos os resultados obtidos encontram-se superiores aos mínimos;

b) Os melhores valores de energia absorvida foram obtidos para o metal base, enquanto os menores valores foram propiciados pela ZTA na condição de como soldado;

c) O TTPS promoveu uma melhoria da tenacidade ao impacto para a ZTA e uma redução desta propriedade para o metal de solda e;

d)A execução do passe de revenimento (PR),promoveu um aumento da tenacidade ao impacto da ZTA para o estado de como soldado.



Figura 9. Variação da energia absorvida a $-30^{\circ} \mathrm{C}$ para as diferentes regiões da junta soldada. 


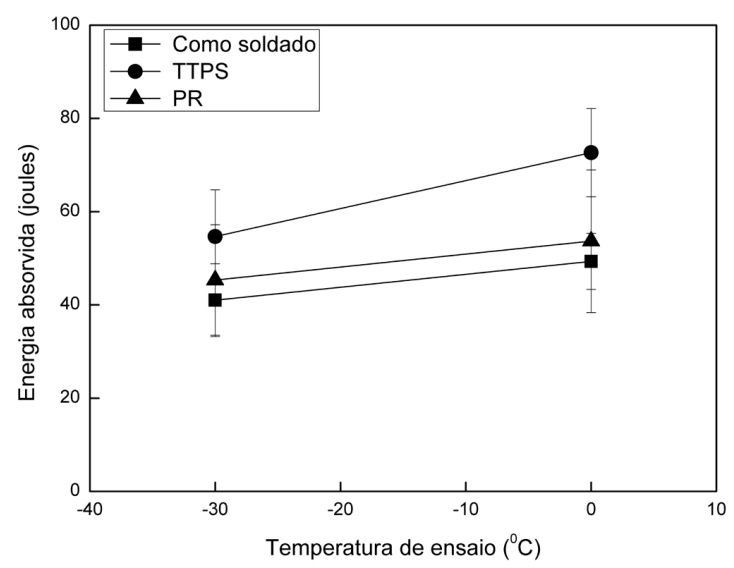

Figura 10. Variação da energia absorvida com a temperatura para a ZTA.

\subsection{Ensaios de microdureza}

As Figuras 11 e 12 mostram os perfis de microdureza Vickers $\left(\mathrm{HV}_{0.5}\right)$ das juntas soldadas, onde se notam as seguintes características:

a) Ocorreu um aumento substancial de dureza na ZTA, na região próxima a linha de fusão, na varredura realizada próxima ao último passe (Figura 11a);

b)Já na varredura realizada na região relativa ao entalhe Charpy-V (Figura 11b), observa-se uma redução substancial na dureza da ZTA;

c) Os maiores valores de dureza foram observados para o estado de como soldado;

d)A execução do passe de revenimento não provocou alterações significativas na dureza;

e) Os valores de dureza apresentam uma redução ao longo da espessura para todas as condições (Figura 12);

f) O TTPS promoveu uma redução substancial na dureza da ZTA; e

g) A dureza do metal de solda acompanhou o comportamento da ZTA para as diversas condições, embora com diferenças menores nos valores obtidos.
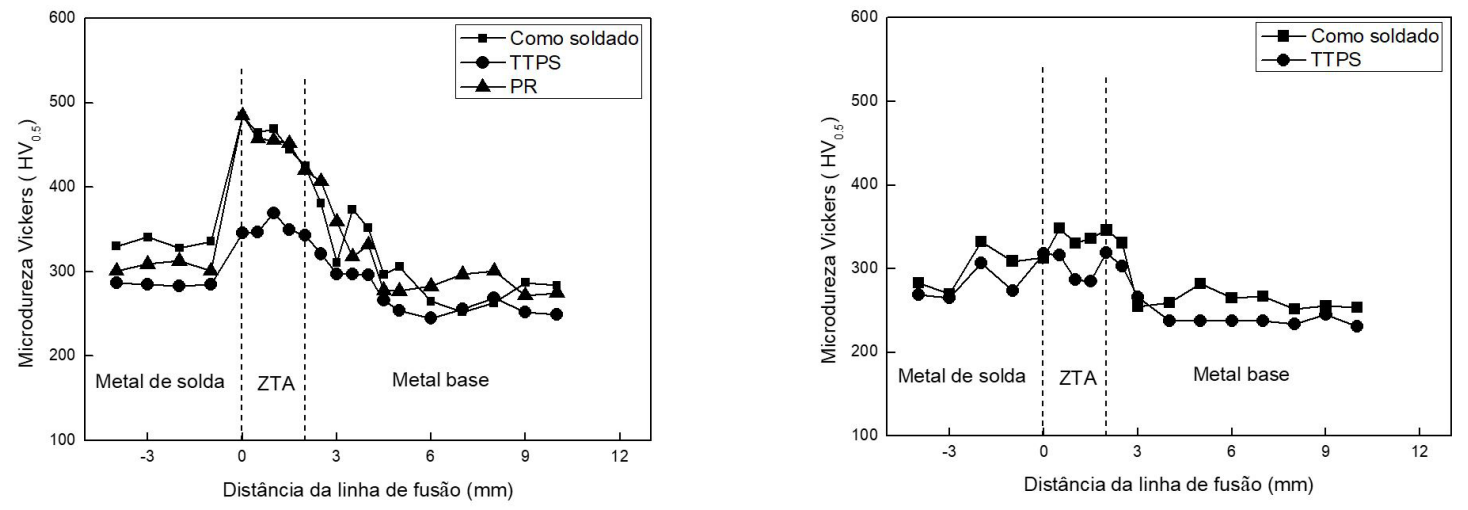

Figura 11. Perfil de microdurezaVickers $\left(\mathrm{HV}_{0.5}\right)$ da junta soldada. 


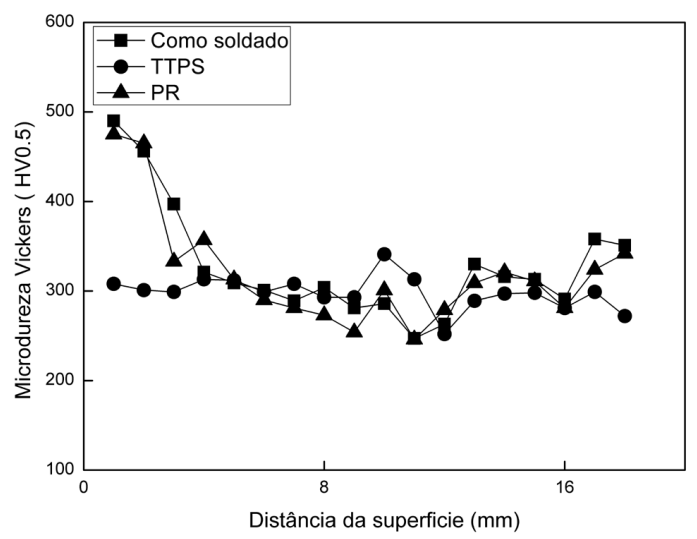

Figura 12. Perfil de microdurezaVickers $\left(\mathrm{HV}_{0.5}\right)$ ao longo da ZTA.

\subsection{Ensaios metalográficos}

A Figura 13 mostra a macrografia da junta soldada, onde se nota o aspecto da soldagem multipasse. A inspeção visual da seção macrográfica não revela a presença de descontinuidades.

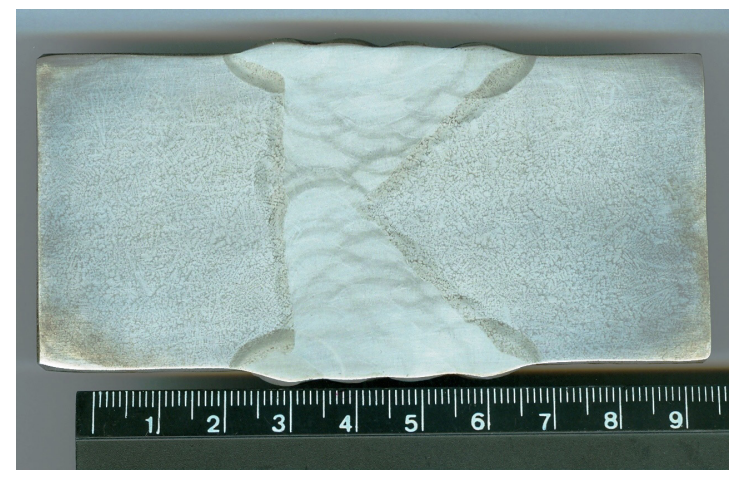

Figura 13. Macrografia da junta soldada. Ataque: nital $2 \%$.

As Figuras 14 a 17 apresentam as microestruturas nas diferentes regiões da junta soldada observadas por microscopia eletrônica de varredura (MEV), onde se percebem as seguintes características principais:

a) Na região do último passe, observa-se a ocorrência de martensita na região de grãos grosseiros da ZTA (RGGZTA) (Figura 14);

b)A execução do passe de revenimento promoveu um revenido da martensita do último passe da RGGZTA (Figura 14);

C) A microestrutura do metal de solda da região do último passe é constituída de martensita (M) e bainita (B) com predominância do primeiro constituinte;

d)O TTPS promoveu um revenido na microestrutura da região do último passe da RGGZTA, evidenciado por extensa precipitação de carbetos (Figura 15);

e) Na região do entalhe Charpy-V (Figura 16), verifica-se um efeito pronunciado de precipitação de carbetos como consequência do efeito do reaquecimento dos diversos passes de soldagem;

f) A mudança do aspecto da microestrutura da RGGZTA ao longo da espessura é mostrada na Figura 17; e

g) O TTPS promoveu extensa precipitação e carbetos nos contornos de grão da austenita prévia do metal de solda (Indicado por setas nas Figuras 14 e 16). 


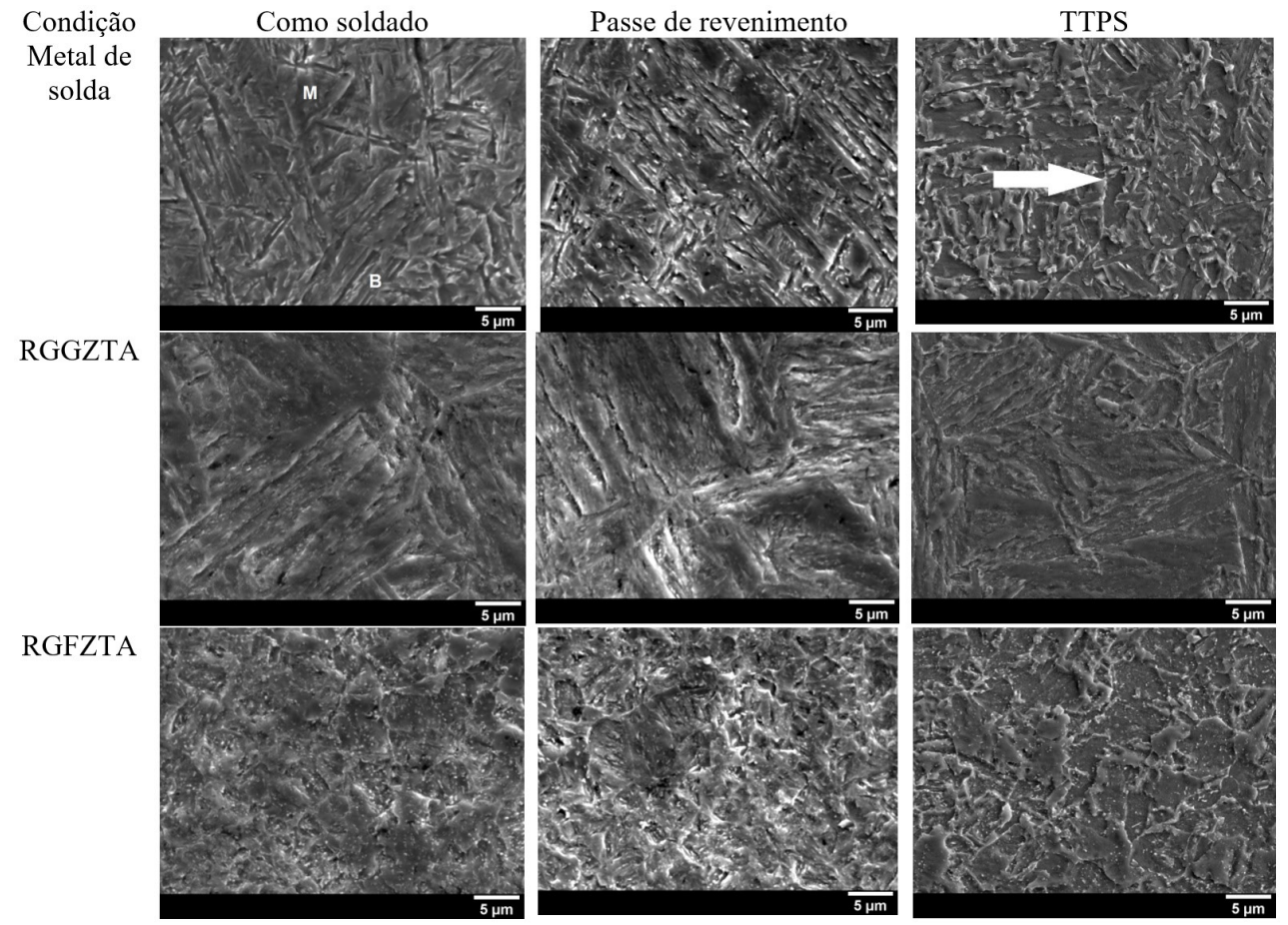

Figura 14. Microestruturas da região do último passe (MEV). Ataque: nital $2 \%$.

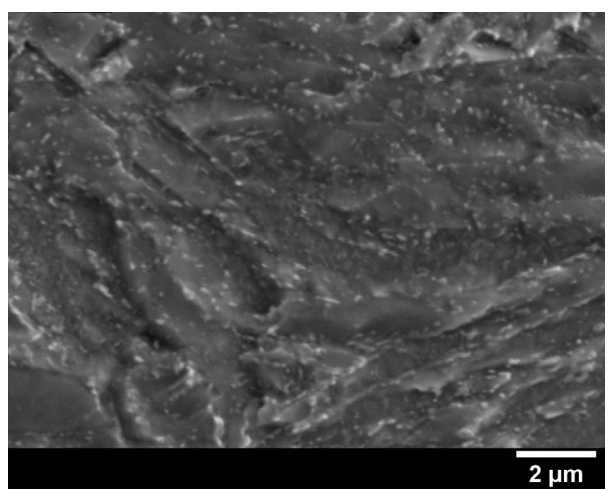

Figura 15. Precipitação de carbetos na região de grãos grosseiros da ZTA após TTPS (MEV). Ataque: nital 2\%.

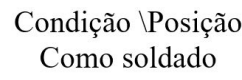

TTPS
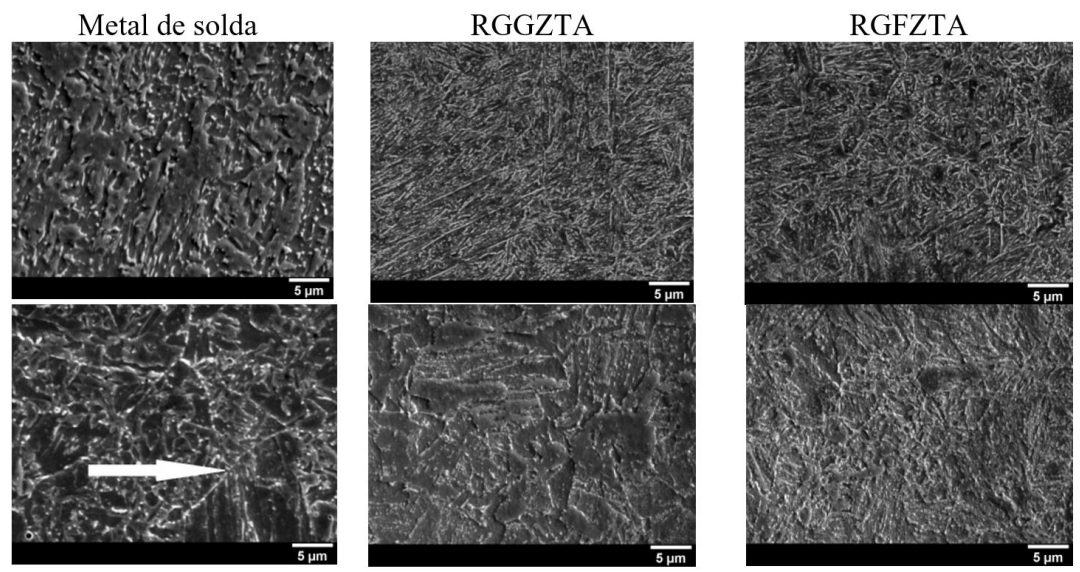

Figura 16. Microestruturas observadas na região central do entalhe do Charpy-V da junta soldada (MEV). Ataque: nital $2 \%$. 


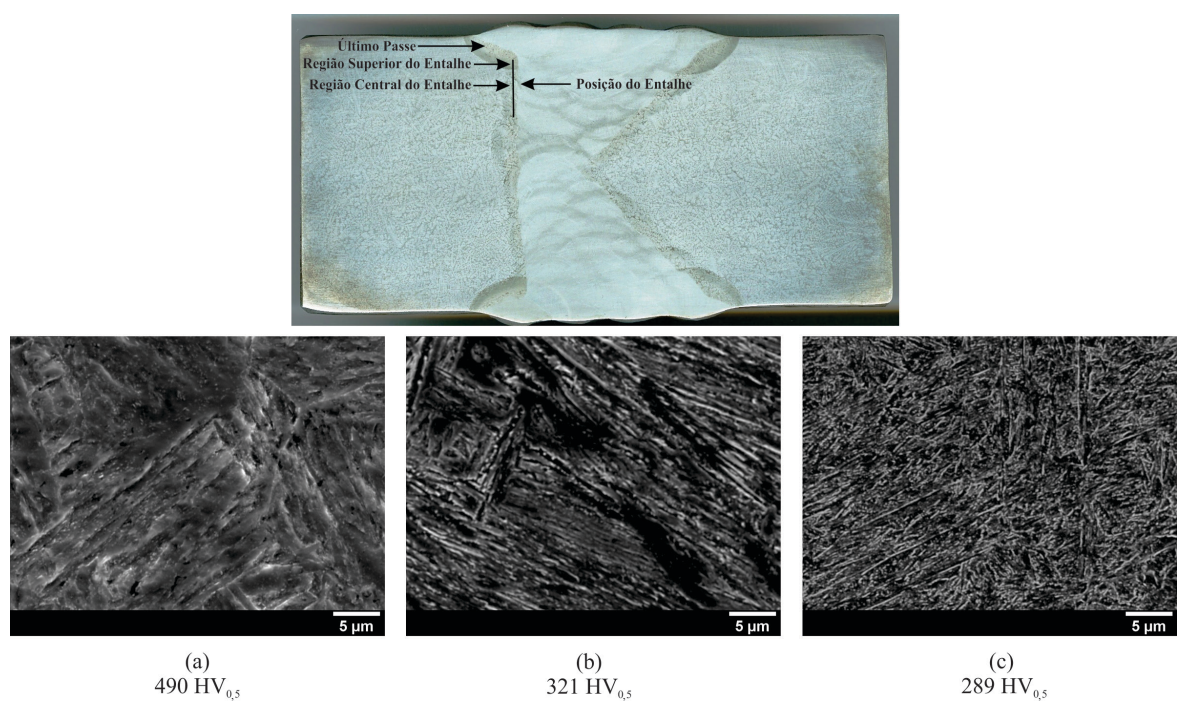

Figura 17. Aspecto da região de grãos grosseiros da ZTA para diversas condições (MEV). Ataque: nital 2\%. (a) Último passe; (b) Região superior do entalhe Charpy-V; (c) Região central do entalhe Charpy-V.

As Figuras 18 e 19 mostram os resultados da análise por EBSD realizada na região de grãos grosseiros da ZTA na posição relativa a ponta do entalhe Charpy-V, onde se notam as seguintes características:


Figura 18. Características microestruturais da região de grãos grosseiros da ZTA analisada por EBSD.

(a) Como soldado (b) TTPS.

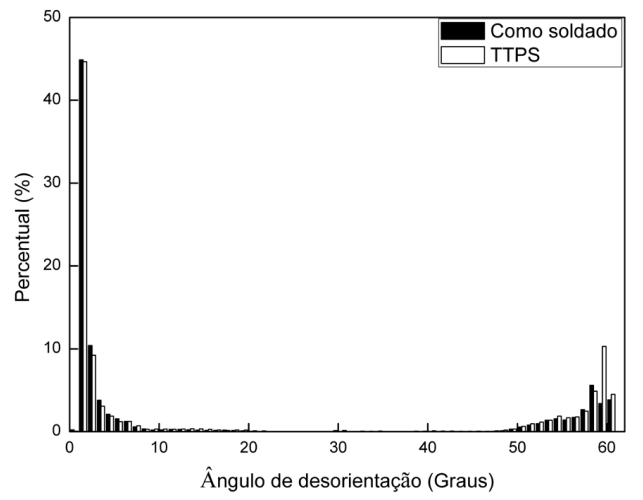

Figura 19. Comportamento de orientação relativa de grãos da RGGZTA. 
a) As FPI indicam os blocos de martensita revenida em um mesmo grão austenítico prévio que apresentam a mesma orientação cristalográfica (Figura 18a, b);

b)A distribuição de contornos de grão é mostrada na Figura 19. A análise estatística da frequência de contornos de alto ângulo indica resultados próximos para as condições, ou seja, 33,45\% para a condição de como soldado e 33,19\% após TTPS; e

c) De uma maneira, geral, a análise por EBSD indicou um comportamento similar para as duas condições estudadas.

\subsection{Simulação termodinâmica}

A Figura 20 apresenta o diagrama com a fração em massa das fases formadas ao longo da temperatura, considerando a composião química do metal base. A temperatura do TTPS é indicada no diagrama. Nota-se que, para esta temperatura, são estáveis os carbetos $\mathrm{M}_{3} \mathrm{C}$ (cementita) para o metal de base.

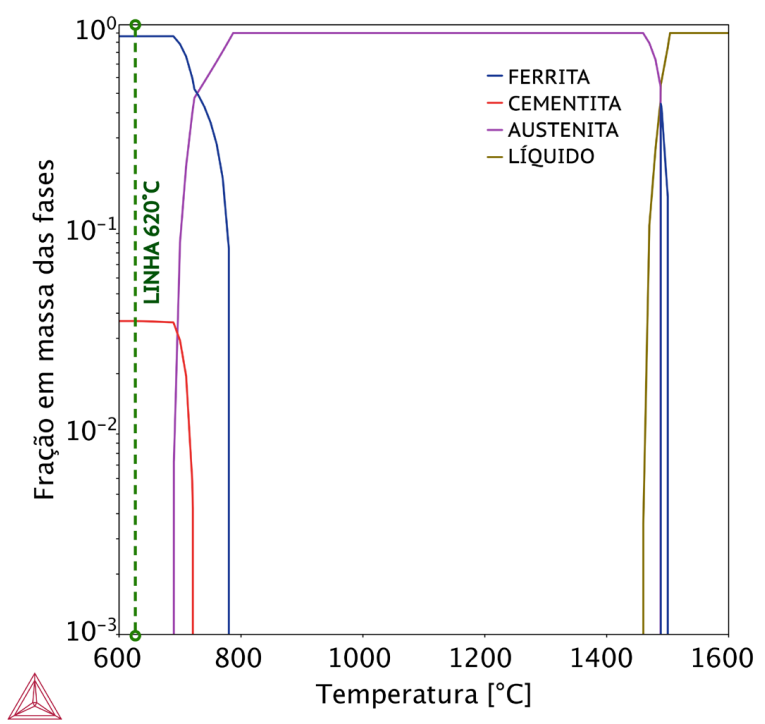

Figura 20. Diagrama de fração de fases formadas com a temperatura para a ZTA. A linha verde tracejada marca a temperatura de TTPS.

\section{Discussão}

\subsection{Propriedades da junta soldada}

A análise macrográfica realizada (Figura 13) permite verificar o efeito da soldagem multipasse e a inexistência de defeitos de soldagem, confirmando que o procedimento de soldagem executado foi adequado para evitar a ocorrência de trinca a frio. Neste aspecto, é importante ressaltar que o material em estudo (Tabela 2) apresenta elevada temperabilidade e, consequentemente, alta propensão para formação de martensita na ZTA, notadamente na região de grãos grosseiros, considerada a região crítica da ZTA [37-43], o que foi observado no presente trabalho (Figura 14).

Os ensaios de tração realizados nas juntas soldadas (Tabela 4) evidenciam a obtenção de elevados valores de resistência mecânica para as juntas soldadas como consequência dos constituintes microestruturais presentes (Figura 16), os quais são esperados para aços temperados e revenidos utilizados nestas aplicações [3,4,13,21,42,44,45]. Adicionalmente, nota-se que todos os corpos de prova romperam no metal base com valores de LE e LR superiores aos mínimos (Tabela 4), caracterizando que o ciclo térmico de soldagem não provocou efeitos nocivos nas propriedades de tração. Embora com dispersão, o mesmo comportamento foi observado após o TTPS, o que seria esperado, visto que as temperaturas de TTPS utilizadas não foram superiores a do tratamento térmico prévio do metal base. 
Segundo a literatura [42,43,46,47], em aços temperados e revenidos de alta resistência e tenacidade, a soldagem produz um efeito de endurecimento local na ZTA em função de formação de constituintes de baixa temperatura de transformação (martensita ou bainita), sendo que o gradiente de dureza normalmente mostra o máximo para a região próxima a linha de fusão com a progressiva redução ao se afastar desta região, o que também foi observado no presente trabalho (Figura 11). Assim, de forma diferente ao comportamento de ensaios de tração e impacto Charpy-V, os resultados de microdureza (Figuras 11 e 12) são capazes de evidenciar as diferenças que ocorrem próximo à superfície da junta soldada, região onde o efeito do reaquecimento não é verificado na condição de como soldado (Figura 12). Como esperado, a microdureza na ZTA desta região apresenta os maiores valores para a junta soldada (Figura 11) devido a presença de martensita sem revenido (Figura 14), conforme também observado por outros autores [42]. Além disso, é importante notar que, mesmo com o passe de revenimento, a dureza desta região não sofreu uma redução tão significativa quanto aquela proporcionada pela execução do TTPS (Figuras 11 e 12).

Já na região da ponta do entalhe Charpy-V (Figura 11b), o comportamento é diferente, com os valores de microdureza significativamente inferiores aos da superfície, o que pode ser atribuído ao reaquecimento dos diversos passes de soldagem, que contribui para uma alteração microestrutural importante na ZTA, onde se nota o efeito de revenido na martensita da ZTA com extensa precipitação de carbetos (Figura 17).

Os resultados obtidos nos ensaios de impacto Charpy-V (Figuras 9 e 10), parecem indicar que não existem diferenças importantes na tenacidade da ZTA para as diferentes condições estudadas, embora seja destacado que a tenacidade desta região tanto no estado de como soldado quanto após o passe de revenimento seja inferior a das outras regiões da junta soldada no estado de como soldado. No entanto, como existe um elevado grau de dispersão para estes resultados, entende-se ser mais adequada uma avaliação com o critério do valor mínimo obtido nos ensaios, o que segundo Li et al. [48] apresenta importância fundamental sob o aspecto de engenharia e pode limitar a aceitação de materiais para alguns casos específicos, dentre eles os componentes de ancoragem [49], uma vez que o valor mínimo pode representar o comportamento de fratura da junta como um todo [50]. Neste caso, a análise das condições estudadas sob o ponto de vista de valor mínimo (36 joules para a condição como soldado, 38 joules após o passe de revenimento e 45 joules após TTPS), mostra um comportamento diferente daquele observado quando da análise do valor médio (Figura 9), permitindo inferir que a realização do TTPS propiciou uma melhoria na tenacidade ao impacto.

O aumento da tenacidade ao impacto (Figuras 9 e 10) e uma redução na microdureza mesmo na região do último passe da ZTA (Figura 12), pode ser atribuído ao revenido da martensita com extensa precipitação de carbetos nesta região (Figuras 15 e 20), com predominância de cementita, conforme previsto pela análise termodinâmica (Figura 20), o que está de acordo com outros trabalhos experimentais [4,18,45,51-53]

Segundo Lan et al. [40], a tenacidade da ZTA é afetada por diferentes características microestruturais, além dos constituintes presentes, especialmente o efetivo tamanho de grão e a fração de contornos de alto ângulo, uma vez que a presença de contornos de alto ângulo é capaz de contribuir para o impedimento da propagação de trincas. No presente trabalho, não se observou efeito significativo do TTPS neste aspecto (Figuras 18 e 19), o que também foi verificado por Cheng et al. [4], que estudando especificamente aços martensíticos utilizados em amarras de ancoragem, observou que alterações de contornos de grão de alto ângulo foram notadas somente para temperaturas de revenido superiores. Embora alguns autores [54,55] que estudaram aços bainíticos, afirmem que o TTPS promove um aumento dos contornos de alto ângulo, Cheng et al. [4] afirmam que esta alteração é dependente da temperatura de revenido e do tipo de microestrutura existente.

Segundo alguns autores [56,57], embora o TTPS seja essencial após a execução de qualquer reparo por soldagem, há um número de limitações associadas. Por exemplo, o TTPS em grandes componentes de aço de refinarias petroquímicas é extremamente caro e consomem muito tempo, além de ser de difícil realização em geometrias complexas porque requer aquecimento de áreas maiores. Além disso, a execução do TTPS pode causar degradação das propriedades do material, especialmente fluência e resistência à tração. Nestes casos, uma alternativa muito utilizada é a realização de passes de revenimento ("temper bead") com o objetivo de reaquecer, refinar e revenir a ZTA do último passe e promover uma melhoria na tenacidade ao impacto para evitar a necessidade do TTPS [14,56-59].

No caso do presente estudo, o uso da técnica de realização de passe de revenimento, não foi efetivo uma vez que os resultados obtidos em ensaios de dureza e impacto foram próximos de aqueles obtidos na condição de soldagem (Figuras 10 e 12). Como observado em trabalhos disponíveis na literatura, esta técnica parece ser uma alternativa interessante na soldagem de aços com menor resistência mecânica [14,57]. 
Neste aspecto, como citado por Song e Dong [60], embora operações de reparo por soldagem sejam frequentemente realizadas durante a fabricação de estruturas de engenharia para atender os requisitos de qualidade do projeto ou reparar os danos desenvolvidos durante a operação, mais de $50 \%$ dos reparos realizados sem execução de TTPS, resultaram em problemas de trincas em serviço em um período inferior a 1 ano.

Este resultado pode ter uma contribuição significativa das tensões residuais presentes na junta soldada. De fato, Aloraier et al. [57,59] atestam que a execução da técnica de passe de revenimento não apresenta nenhuma contribuição para a redução das tensões residuais, embora possa promover vantagens sob o ponto de vista metalúrgico. É importante comentar que na qualificação de procedimentos de soldagem não é possível realizar uma avaliação do efeito das tensões residuais no comportamento da junta soldada, uma vez que a realização de operações de corte para remoção de corpos de prova para ensaios mecânicos promovem o alívio das tensões [61].

Isto toma importância maior quando se observa a modelagem realizada pelo método de elementos finitos (Figura 7), a qual evidencia que a região crítica em termos de tensão para a operação do equipamento é justamente a região da ZTA que estará suscetível a ocorrência de tensões residuais de magnitude elevada.

A discussão apresentada previamente, indica que um procedimento de soldagem seguro não deve prescindir da realização de TTPS, uma vez que a presença de martensita de elevada dureza na ZTA do último passe associado com elevadas tensões residuais deve ser evitada por apresentar condições propícias para ocorrência fratura frágil no componente.

Embora a execução do TTPS tenha gerado uma redução da tenacidade ao impacto no metal de solda (Figura 9), o que pode estar associado com a ocorrência de precipitação de carbetos nos contornos de grão da austenita prévia (Figuras 14 e 16), conforme também verificado em outras publicações que estudaram especificamente o comportamento de metal de solda de aços de alta resistência [10,26,62-65], os autores acreditam não ser esta uma questão imperativa, uma vez que mesmo com esta redução, os resultados obtidos permanecem como adequados para a aplicação (Figura 9). Adicionalmente, deve ser destacado que é ainda possível a utilização de outros consumíveis de alta resistência com melhor desempenho [13,15,23,62,63].

\subsection{Implicações práticas dos resultados}

O objetivo do presente trabalho é analisar as propriedades mecânicas das juntas soldadas de um aço fundido de alta resistência e sua adequação para utilização em componentes de ancoragem, considerando que em algumas ocasiões esta é a solução recomendada para a fabricação de componentes. A este respeito, embora existam muitos estudos envolvendo o desenvolvimento de aços fundidos para várias aplicações [9,10,12-19,66-71], informações sobre a relação entre propriedades mecânicas e microestruturais das juntas soldadas de aços fundidos para fins estruturais aços ainda são limitadas.

Esta limitação também é observada quando da necessidade da qualificação de procedimentos de soldagem, visto que as normas de soldagem envolvendo os aços fundidos [72-74] podem não apresentar requisitos específicos para a avaliação da tenacidade ao impacto, apenas propondo algumas recomendações genéricas, como a necessidade de realização de tratamento térmico pós-soldagem com o objetivo de alívio de tensões residuais [72]. Assim, a aprovação de juntas soldadas de aços fundidos em componentes da indústria offshore envolve um desafio adicional, visto que é necessária uma adaptação dos requisitos de Livros de Regras de Sociedades Classificadoras Navais [49,75-77] em cada caso específico.

Conforme já discutido previamente, os estudos realizados no presente trabalho concordam com esta necessidade de realização de TTPS não somente do ponto de vista de tensões residuais mas, principalmente, pelo aspecto de haver necessidade de ajuste microestrutural. De fato, embora a literatura [57,59] aponte que a execução da soldagem com aplicação de passe de revenimento possa contribuir para o ajuste das propriedades mecânicas, os resultados obtidos no presente trabalho mostraram que a região do último passe mesmo com o passe de revenimento não atende as condições para uma junta segura.

Uma última questão de interesse, é relativa à conformidade dos resultados aqui discutidos para aplicações de componentes deancoragem, onde se destacam as amarras de aço.

Os elos de amarras de aço são fabricados a partir de barras laminadas circulares, que após conformação para a dimensão final, são soldados por centelhamento $[25,44,78]$ e, posteriormente, submetidos a tratamentos térmicos 
de têmpera e revenido [44] para obtenção das propriedades mecânicas adequadas aos requisitos das Sociedades Classificadoras Navais [74]. A Figura 21 mostra os detalhes de um elo de amarra com malhete.

As amarras são um elemento importante das linhas de ancoragem de plataforma de petróleo e, são submetidas a diversos tipos de mecanismos de desgaste que podem promover a fratura do componente [8,79]. Como a substituição de um único elo pode ser uma tarefa complexa, foram desenvolvidos procedimentos de soldagem de recuperação de elos por soldagem pelo processo eletrodo revestido com desempenho satisfatório em fadiga [21,23], que é o mecanismo mais determinante na fratura dos componentes das linhas de ancoragem [44,80].

A Figura 22 mostra uma comparação dos resultados de tenacidade ao impacto destes estudos [21,23] com os discutidos no presente trabalho. É possível notar que o aço fundido pode propiciar resultados equivalentes aos destes estudos [21,23], mesmo considerando que os aços laminados por terem sido submetidos a processos de conformação mecânica, reúnem características microestruturais mais adequadas para uma boa tenacidade (Figura 23), tais como uma estrutura mais refinada e maior incidência de contornos de alto ângulo $[4,37,52,81-84]$.

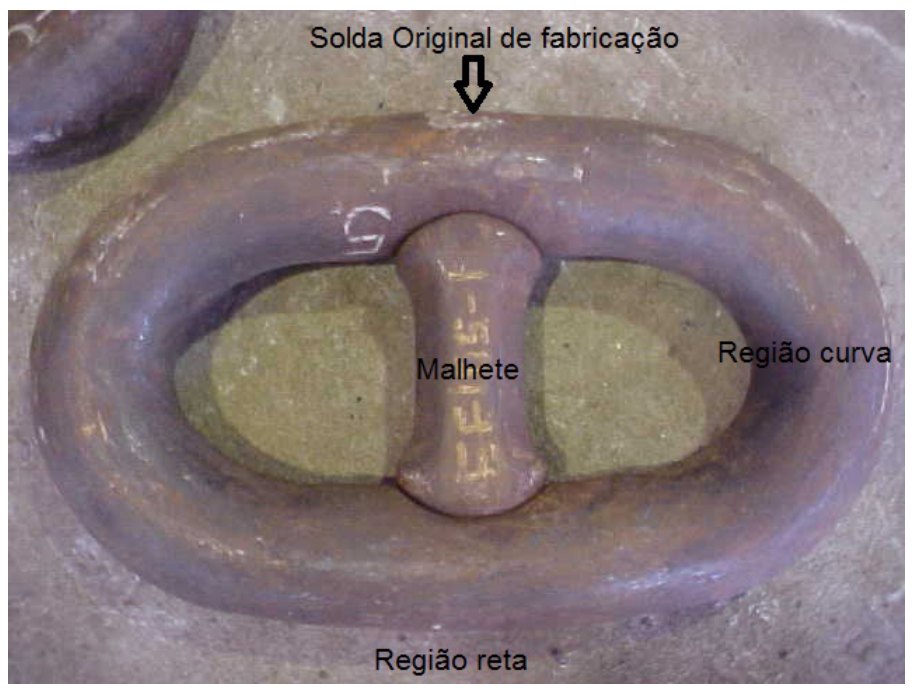

Figura 21. Detalhes do elo de amarra de aço com malhete.

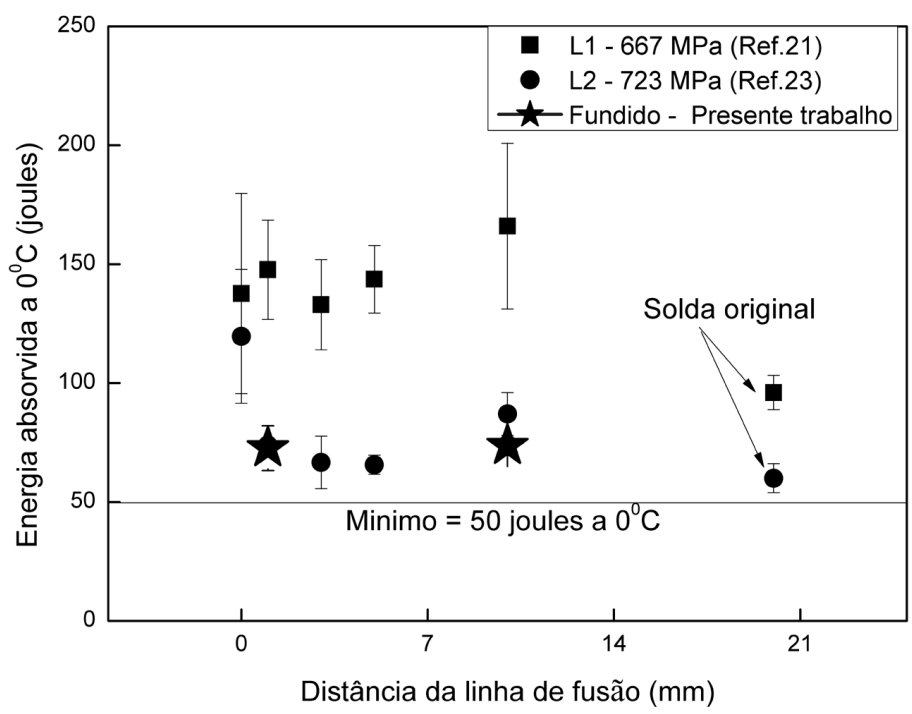

Figura 22. Análise comparativa da tenacidade ao impacto com juntas soldadas de aços laminados [21,23]. 


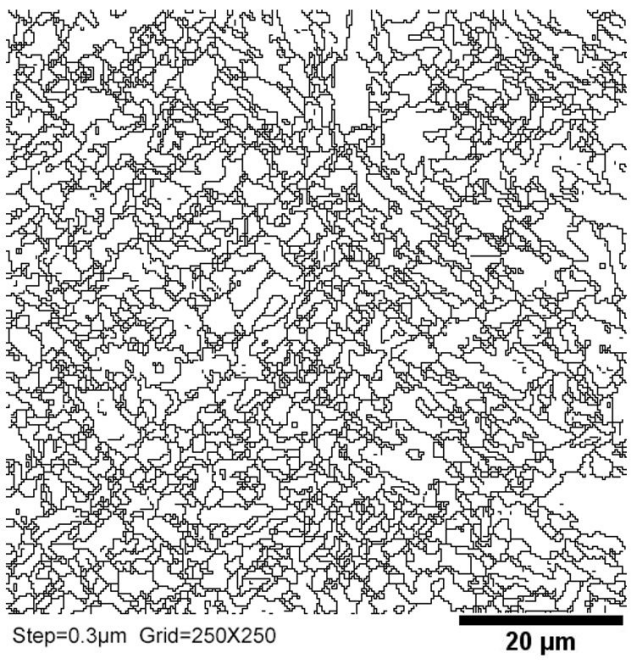

(a)

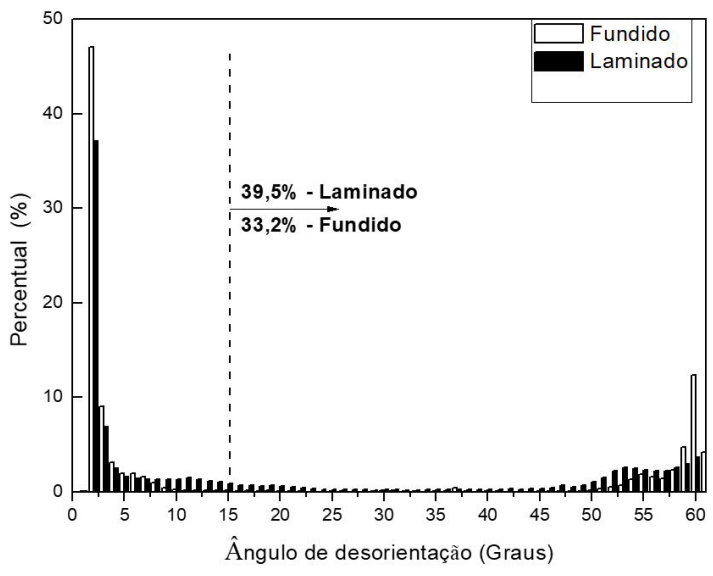

(b)

Figura 23. Comportamento microestrutural da região de grãos grosseiros da ZTA de um aço laminado (aço L1) por EBSD, na região relativa ao entalhe do corpo de prova Charpy-V após TTPS. (a) Mapa de tamanho de grão; (b) Distribuição de contornos de grão comparativo com o aço fundido estudado.

É de destaque ainda o fato que as normas de fabricação de amarras [49] não exigem composição química definida, o que permite que diferentes aços possam ser usados para a fabricação de um mesmo grau de amarra com consequente desvio nos resultados de tenacidade ao impacto [21,23,81,82]. Adicionalmente, nota-se que a solda original de fabricação (SO), região considerada como o ponto crítico do elo de amarra [80,81], pode mostrar valores de energia de impacto inferiores aos da junta de aço fundido.

Este resultado evidencia que além de um comportamento similar ao de aços laminados, o aço em estudo também pode também ser adequado para fabricação de outros componentes de sistemas de ancoragem com requisitos mais críticos [49].

\section{Conclusões}

Com base nos resultados obtidos no presente trabalho, as principais conclusões são:

- O Oço fundido ASTM A 148 Gr. 10585 pode ser soldado pelo processo de eletrodos revestidos e apresentar propriedades mecânicas adequadas para utilização em componentes de ancoragem;

- A execução do tratamento térmico pós-soldagem é recomendado para a garantia das propriedades, uma vez que promove o revenido da martensita de elevada dureza da região do último passe;

- A execução da técnica de passe de revenimento não se mostrou eficaz para as propriedades da junta soldada estudada e;

- A junta soldada de aço fundido, mesmo apresentando uma microestrutura mais grosseira, mostrou propriedades equivalentes a de aços laminados usualmente utilizados na fabricação de componentes de ancoragem.

\section{Agradecimentos}

Os autores agradecem às Instituições pelo apoio prestado na execução do presente trabalho: CEFET/RJ, UFRJ, CTEx, CNPq e FINEP. 


\section{Referências}

[1] Sabziyan H, Ghassemi H, Azarsina F, Kazemi S. Effect of mooring lines pattern in a semi-submersible platform at surge and sway movements. Journal of Ocean Research. 2014;2(1):17-22.

[2] Gonçalves RCF, Costa LCS. Inspeção em linhas de ancoragem de unidades de produção. In: Anais do 21 o Congresso Nacional de Ensaios não Destrutivos; 2002 Ago 19-22; Salvador, Brasil. São Paulo: ABENDI; 2002. p. 1-9.

[3] Cheng X, Zhang H, Liu W, Zhang Z. Influence of mooring chain steel strength on stress corrosion cracking. Applied Mechanics and Materials. 2013;404:32-39. http://dx.doi.org/10.4028/www. scientific.net/AMM.404.32.

[4] Cheng XY, Zhang HX, Li H, Shen HP. Effect of tempering temperature on the microstructure and mechanical properties in mooring chain steel. Materials Science and Engineering A. 2015;636:164-171. http://dx.doi.org/10.1016/j.msea.2015.03.102.

[5] Angulo A, Edwards G, Soua S, Gan T-H. Mooring integrity management: novel approaches towards in situ monitoring. In: Rivas-Lopez M, editor. Structural health monitoring: measurement methods and practical applications. London: Intechopen; 2017. Chap. 5. http://dx.doi.org/10.5772/intechopen.68386.

[6] López A, Bayón R, Pagano F, Igartua A, Arredondo A, Arana $\mathrm{JL}$, et al. Tribocorrosion behavior of mooring high strength low alloy steels in synthetic seawater. Wear. 2015;338-339:1-10. http://dx.doi.org/10.1016/j.wear.2015.05.004.

[7] Sagrilo LVS, Sousa JRM, Lima ECP, Porto EC, Fernandes JVV. A study on the holding capacity safety factors for torpedo anchors. Journal of Applied Mathematics. 2012:1-18. http://dx.doi. org/10.1155/2012/102618.

[8] Kvitrud A. Lessons learned from the norwegian mooring lines failures 2010-2013. In: Proceedings of the ASME 33rd International Conference on Ocean, Offshore and Arctic Engineering (OMAE); 2014 June 8-13; San Francisco, USA. San Francisco: ASME; 2014. p. 1-10.

[9] Chaves AP. Estudo comparativo da vida em fadiga de aços fundidos e forjados de aços de alta resistência para utilização em acessórios de linhas de ancoragem de plataformas offshore [dissertação de mestrado]. Rio de Janeiro: Programa de Pós-graduação em Engenharia Mecânica e Tecnologia de Materiais, Centro Federal de Educação Tecnológica; 2010.

[10] Oliveira EM, Jorge JCF, Souza LFG. Efeito de tratamento térmico pós-soldagem nas propriedades mecânicas de juntas soldadas de aço fundido de alta resistência mecânica. In: Anais do $69^{\circ}$ Congresso Internacional da ABM; 2014 Jul 21-25; São Paulo, Brasil. São Paulo: Associação Brasileira de Metalurgia e Materiais; 2014. p. 1-12.

[11] Costa LCS, Castro GAV, Gonçalves RCF, Araújo RT. Polyester mooring systems - petrobras experience. In: Proceedings of the Deep Offshore Technology Conference; 2001 Sept 17-21; Rio de Janeiro, Brasil. Tulsa: PennWell Corporation; 2001. p. 1-17.

[12] Santos OR Fo, Santos AMF Fo, Diniz JLC, Jorge JCF, Souza LFG. Mechanical and microstructural properties of high strength cast Steel repaired by welding, In: Anais do 42 을 Congresso Nacional de Soldagem; 2016 Nov 28-30; Belo Horizonte; Brasil. São Paulo: ABS; 2016. p. 1-8.

[13] Mosciaro HB, Jorge JCF. Avaliação de procedimentos de reparos soldados para estruturas offshore em aços fundidos de alta resistência. Technology and Culture. 1997;1(1):41-45.

[14] Jorge JCF, Souza LFG, Santos OR Fo, Santos AMF Fo, Bott IS, Guimarães FHB. Relação tenacidade/microestrutura da ZTA de aço fundido ASTM A $148 \mathrm{Gr}$. 80-50 para acessórios de ancoragem de plataformas de petróleo. Soldagem e Inspeção. 2004;9(4):192197.

[15] Sumam JA, Jorge JCF, Souza LFG, Bott IS. Efeito de tratamentos térmicos pós-soldagem nas propriedades de aço fundido de elevada resistência para sistemas deancoragem de plataformas marítimas. Soldagem e Inspeção. 2004;9(4):205-212.

[16] Diniz WG, Bracarense AQ, Silva GM. Avaliação das propriedades mecânicas de um aço fundido de baixo carbono, como função da sequência de processos de tratamento térmico e soldagem. In: Anais do $8^{\circ}$ Congresso Brasileiro de Engenharia de Fabricação; 2015 Maio 18-22; Salvador, Brasil. Salvador: ABCM; 2015. p. 1-8.

[17] Santos OR Fo, Santos AMF Fo, Vieira RD, Souza LFG, Pacheco PMCL, Jorge JCF. Avaliação de juntas soldadas de aços fundidos para construção naval. In: Anais do $14^{\circ} \mathrm{CBECIMAT}$; 2000; São Pedro, Brasil. São Paulo: IPEN; 2010. p. 37901-37913.

[18] Bolouri A, Kim TW, Kang CG. Processing of low-carbon cast steels for offshore structural applications. Materials and Manufacturing Processes. 2013;28(11):1260-1267. http://dx.doi.org/10.1080/1 0426914.2013 .792424$.

[19] Lim S, Mun J, Kim T, Kang C. Development of low-temperature high-strength integral steel castings for offshore construction by casting process engineering. International Journal of Naval Architecture and Ocean Engineering. 2014;6(4):922-934. http:// dx.doi.org/10.2478/IJNAOE-2013-0222.

[20] American Society for Testing and Materials. ASTM A 148/A 148M08: standard specification for steel castings, high strength, for structural purposes. West Conshohocken: ASMT; 2008.

[21] Jorge JCF, Souza LFG, Pacheco PMCL, Vieira RD, Kenedi PP, Santos AMF Fo, et al. Desenvolvimento de procedimento de reparo por soldagem de marras de aço para ancoragem de plataformas de petróleo. In: Anais do $27^{\circ}$ Congresso Nacional de Soldagem; 2001 Out 7-10; Campinas, Brasil. São Paulo: ABS; 2001. p. 1-10.

[22] Leal SNCC. Corrosão em elos de amarras offshore: um estudo de caso [dissertação de mestrado]. Rio de Janeiro: Programa de Pós-graduação em Engenharia Metalúrgica, Pontifícia Universidade Católica do Rio de Janeiro; 2003.

[23] Jorge JCF, Souza LFG, Kenedi PP, Pacheco PMCL, Diniz JLC, Santos OR Fo. Performance evaluation of high strength steel chain links welded by SMAW process submitted to fatigue testing. In: Anais do $7^{\circ}$ Congresso Nacional de Engenharia Mecânica; 2012 jul. 31-ago. 3; São Luiz, Brasil. Rio de Janeiro: ABCM; 2012. p. 1-9.

[24] Pimenta JMP. Modificações nas propriedades mecânicas e na resistência à fratura do aço estrutural R4 [dissertação de mestrado]. Rio de Janeiro: Programa de Pós-graduação em Engenharia Metalúrgica, Pontifícia Universidade Católica do Rio de Janeiro; 2007.

[25] Kim DC, So WJ, Kang MJ. Effect of flash butt welding parameters on weld quality of mooring chain. Arquives of Materials Science and Engineering. 2009;38(2):112-117.

[26] Salvador LSF. Efeito da composição química e tratamento térmico pós-soldagem nas propriedades de metal de solda de aços de alta resistência [dissertação de mestrado]. Rio de Janeiro: Centro Federal de Educação Tecnológica Celso Suckow da Fonseca; 1997.

[27] Coelho WP, Nogueira YRG. Soldagem do aço 8630 modificado [trabalho de conclusão de curso]. Belo Horizonte: Universidade Federal de Minas Gerais; 2015.

[28] Duarter SMA, Costa EC, Almeida JG, Cavalcante FJN, Lima SJG. Caracterização do aço AISI 8630M amanteigado com o arame ER80S-D2 pelo processo de soldagem "MAG". In: Anais do 8ㅇ 
Congresso Brasileiro de Engenharia de Fabricação; 2015 Maio 18-22; Salvador, Brasil. Rio de Janeiro: ABCM; 2015. p. 1-10.

[29] Batista R, Araújo EM, Fraga R, Maciel TM. Caracterização a interface de depósitos de solda de Inconel 625 sobre aços AISI 8630 e AISI 4130 temperados e revenidos. In: Anais do 220 Congresso Brasileiro de Engenharia e Ciência dos Materiais; 2016 Nov 6-10, Natal, Brasil. São Paulo: Metallum Congressos Técnicos e Científicos. p. 1-14.

[30] Dai T, Lippold JC. Tempering effect on the fusion boundary region of alloy 625 weld overlay on 8630 steel. Welding in the World. 2018;62(3):535-550. http://dx.doi.org/10.1007/s40194-0180560-3.

[31] Dodge MF, Dong HB, Gittos MF, Mobberley T. Fusion zone microstructure associated with embrittlement of subsea dissimilar joints. In: Proceedings of the $33^{\circ}$ International Conference on Ocean, Offshore and Arctic Engineering OMAE2014; 2014 June 8-13; San Francisco, CA. USA: ASME; 2014. http://dx.doi. org/10.1115/OMAE2014-23643.

[32] Elias MS, Paranhos R. Avaliação metalúrgica da soldagem de revestimento inox austenítico sobre aço SAE 4130. Soldagem e Inspeção. 2014;19(4):343-352. http://dx.doi.org/10.1590/01049224/SI1904.07.

[33] Sagrilo LVS, Sousa JRM, Lima ECP, Porto EC, Fernandes JVV. A study on the holding capacity safety factors for torpedo anchors. Journal of Applied Mathematics. 2012;2012:1-18. http://dx.doi. org/10.1155/2012/102618.

[34] Soh EP, Pao W, Al-Kayiem HH. Numerical analyses for improved hydrodynamics of deep water torpedo anchor. IOP Conference Series: Materials Science and Engineering. 2015;100:012059. http://dx.doi.org/10.1088/1757-899X/100/1/012059.

[35] American Welding Society. Specification for low alloy steel electrodes for shielded metal arc welding - AWS 5.5. Miami: AWS; 1996.

[36] ASTM International. Standard test methods and definitions for mechanical testing of steel products - ASTM A-370-05, 2005. West Conshohocken: ASTM; 2005.

[37] Wang Y, Kannan R, Zhang L, Li L. Microstructural analysis of the as welded heat affected zone of a grade 91 steel heavy section weldment. Welding Journal. 2017;96(3):203s-219s.

[38] Spachinger SJ, Ernst W, Enzinger N. Influence of Ti on the toughness of the FGHAZ and the CGHAZ of high-strength microalloyed S700MC steels. Welding in the World. 2017;61(6):1117-1131. http://dx.doi.org/10.1007/s40194-017-0480-7.

[39] Zhou Y, Jia T, Zhang X, Liu Z, Misra RDK. Microstructure and toughness of the CGHAZ of an offshore platform steel. Journal of Materials Processing Technology. 2015;219:314-320. http:// dx.doi.org/10.1016/j.jmatprotec.2014.12.017.

[40] Lan L, Qiu C, Zhao D. EBSD analysis of HAZ microstructure characteristics of a high strength low welding crack susceptibility steel. Advanced Materials Research. 2011;152-153:852-855. http://dx.doi.org/10.4028/www.scientific.net/AMR.152-153.852.

[41] Park DY, Amirkhiz BS, Gravel JP, Wang Y, Li L, Zavadil R, et al. Effects of heat-affected zone microstructure on fracture toughness of two X70 pipe girth welds. Metallurgical and Materials Transactions. A, Physical Metallurgy and Materials Science. 2017;48A(7):32483260. http://dx.doi.org/10.1007/s11661-017-4100-3.

[42] Gao W, Wang D, Cheng F, Di X, Deng C, Xu W. Microstructural and mechanical performance of underwater wet welded $\mathrm{S} 355$ steel. Journal of Materials Processing Technology. 2016;238:333-340. http://dx.doi.org/10.1016/j.jmatprotec.2016.07.039.

[43] Rabiei A, Derakhshandeh-Haghighi R. Studying the effect of PWHT on microstructural evolution and mechanical properties of welded A517 quenched and tempered steel. Journal of Materials Engineering and Performance. 2017;26(9):4567-4577. http:// dx.doi.org/10.1007/s11665-017-2868-3.

[44] Carneiro MA, Pereira MVS, Darwish FA, Motta SH. Propagação de trincas de fadiga em aço estrutural após soldagem por centelhamento. Soldagem e Inspeção. 2008;13(1):2-10.

[45] Lee KH, Jhung MJ, Kim MC, Lee BS. Effects of tempering and PWHT on microstructures and mechanical properties of SA508 Gr.4N steel. Nuclear Engineering and Technology. 2014;46(3):413-422. http://dx.doi.org/10.5516/NET.07.2013.088.

[46] Dunne DP, Pang W. Displaced hardness peak phenomenon in heat-affected zone of welded quenched and tempered EM812 steel. Welding in the World. 2017;61(1):57-67. http://dx.doi. org/10.1007/s40194-016-0385-x.

[47] Poorhaydari K, Ivey DG. Heat-affected zone property diagrams for a grade 100 microalloyed steel. Welding in the World. 2018;62(3):1-14. http://dx.doi.org/10.1007/s40194-018-0563-0.

[48] LiXD, MaXP, Subramanian SV, Shang CJ, Misra RDK. Influence of prior austenite grain size on martensite-austenite constituent and toughness in the heat affected zone of $700 \mathrm{MPa}$ high strength linepipe steel. Materials Science and Engineering A. 2014;616:141147. http://dx.doi.org/10.1016/j.msea.2014.07.100.

[49] International Association of Classification Societies. Specification W22, Offshore Mooring Chain. London: IACS; 2016.

[50] Wang XL, Wang ZQ, Ma XP, Subramanian SV, Xie ZJ, Shang CJ, et al. Analysis of impact toughness scatter in simulated coarse-grained HAZ of E550 grade offshore engineering steel from the aspect of crystallographic structure. Materials Characterization. 2018;140:312319. http://dx.doi.org/10.1016/j.matchar.2018.03.037.

[51] Lee K, Chien YC. A sudy of microstructure and mechanical properties of thick welded joints of a Cr-Mo steel. Metal Science and Heat Treatment. 2015;57(3-4):175-180. http://dx.doi.org/10.1007/ s11041-015-9858-6.

[52] Zhao MS, Chiew SP, Lee CK. Post weld heat treatment for high strength steel welded connections. Journal of Constructional Steel Research. 2016;122:167-177. http://dx.doi.org/10.1016/j. jcsr.2016.03.015.

[53] Zhou Y, Jia T, Zhang X, Liu Z, Misra RDK. Investigation on tempering of granular bainite in an offshore platform steel. Materials Science and Engineering A. 2015;626:352-361. http://dx.doi. org/10.1016/j.msea.2014.12.074.

[54] Wang Y, Li L. Microstructure evolution of fine-grained heataffected zone in Type IV failure of P91 welds. Welding Journal. 2016;95(1):27s$36 \mathrm{~s}$.

[55] Zhang J, Cai Q, Wu H, Zhang K, Wu B. Effect of tempering temperature on microstructure and properties of E690offshore plate steel. Journal of Iron and Steel Research International. 2012;19(3):6772. http://dx.doi.org/10.1016/S1006-706X(12)60076-4.

[56] Ling K-H, Fuh Y-K, Kuo T-C, Xun-Tu S. Effect of welding sequence of a multi-pass temper bead in gas-shielded flux-cored arc welding process: hardness, microstructure, and impact toughness analysis. International Journal of Advanced Manufacturing Technology. 2015;81(5-8):1033-1046. http://dx.doi.org/10.1007/s00170-0157277-x.

[57] Aloraier AS, JoshiS, Price JWH, Alawadhi K. Hardness, microstructure, and residual stresses in low carbon steel welding with post-weld heat treatment and temper bead welding. Metallurgical and Materials Transactions. A, Physical Metallurgy and Materials Science. 2014;45A(4):2030-2037. http://dx.doi.org/10.1007/ s11661-013-2170-4.

[58] Brziak P, Lomozik M, Mizuno R, Matsuda F. Repair welding of SQV2A pressure vessel steel by temper bead techniques 
without post welding heat treatment. Archives of Metallurgy and Materials. 2011;56(2):205-216. http://dx.doi.org/10.2478/ v10172-011-0024-x.

[59] Aloraier AS, Al-Mazrouee A, Price JWH, Shehata T. Weld repair practices without post weld heat treatment for ferritic alloys and their consequences on residual stresses: A review. International Journal of Pressure Vessels and Piping. 2010;87(4):127-133. http:// dx.doi.org/10.1016/j.ijpvp.2010.02.001.

[60] Song S, Dong P. Residual stresses at weld repairs and effects of repair geometry. Science and Technology of Welding and Joining. 2017;22(4):265-277. http://dx.doi.org/10.1080/13621718.2016. 1224544 .

[61] Vieira RD, Jorge JCF, Freire JLF, Castro JTP. Medição de tensões residuais em peças fundidas com reparo soldado. In: Anais do $3^{\circ}$ Seminário Latino-americano de Inspeção de Equipamentos; 1995; Foz do Iguaçu, Brasil. Rio de Janeiro: IBP; 1995. p. 39-46.

[62] Gomes AJM, Jorge JCF, Souza LFG, Bott IS. Influence of chemical composition and post welding heat treatment on the microstructure and mechanical properties of high strength steel weld metals. Materials Science Forum. 2013;758:21-32. http:// dx.doi.org/10.4028/www.scientific.net/MSF.758.21.

[63] Jorge JCF, Faragasso SM, Souza LFG, Bott IS. Effect of post welding heat treatment on the mechanical and microstructural properties of extra high-strength steel weld metals for application on mooring equipment. Welding International. 2015;29(7):521-529. http:// dx.doi.org/10.1080/09507116.2014.932984.

[64] Jorge JCF, Souza LFG, Couto JLC, Bott IS. Influence of chemical composition on the mechanical properties of high strength steel weld metals for application in mooring components. International Journal of Engineering and Technical Research. 2016;4(2):71-76.

[65] Queiroz SS, Jorge JCF, Souza LFG, Bott IS. Efeito das condições de soldagem nas propriedades mecânicas de metais de solda de aços de alta resistência obtidos pelo processo GMAW. In: Associação Brasileira de Metalurgia e Materiais. Anais do $71^{\circ}$ Congresso Anual da ABM; 2016 set 26-30; Rio de Janeiro, Brasil. São Paulo: ABM; 2016. p. 679-686. http://dx.doi.org/10.5151/1516-392X-27750.

[66] Zhao J, Jiang Z, Lee CS. Enhancing impact fracture toughness and tensile properties of a microalloyed cast steel by hot forging and post-forging heat treatment processes. Materials \& Design. 2013;47:227-233. http://dx.doi.org/10.1016/j.matdes.2012.11.051.

[67] Ghosh S, Mula D, Mondal DK. Development of ultrahigh strength cast-grade microalloyed steel by simple innovative heat treatment techniques for industrial applications. Materials Science and Engineering A. 2017;700:667-680. http://dx.doi.org/10.1016/j. msea.2017.06.054.

[68] Dhanishta S, Jadoun RS, Dixit N. Developing welding procedure to repair of casting defects for grade P91 steels by welding with matching electrode. MIT International Journal of Mechanical Engineering. 2016;6(1):28-32.

[69] $\operatorname{Kim~T,~Lim~S,~Seok~H,~Kang~C.~Concurrent~engineering~solution~}$ for the design of ship and offshore bracket parts and fabrication process. International Journal of Naval Architecture and Ocean Engineering. 2013;5(3):376-391. http://dx.doi.org/10.2478/ IJNAOE-2013-0140.

[70] Kang SS, Bolouri A, Kang C. The effect of heat treatment on the mechanical properties of a low carbon steel $(0.1 \%)$ for offshore structural application. Journal of Materials Design and Applications. 2012;226(3):242-251.
[71] Lim S, Mun J, Kim T, Kang C. Development of low-temperature high-strength integral steel castings for offshore construction by casting process engineering. International Journal of Naval Architecture and Ocean Engineering. 2014;6(4):922-934. http:// dx.doi.org/10.2478/IJNAOE-2013-0222.

[72] American Society for Testing and Materials. ASTM-488: standard practice for steel castings, welding, qualifications of procedures and personnel. West Conshohocken: ASTM International; 2012.

[73] International Association of Classification Societies. W8, Hull and machinery steel castings. London: IACS; 2004.

[74] International Association of Classification Societies. W28, Welding procedure qualification tests of steels for hull construction and marine structures. London: IACS; 2012.

[75] American Bureau of Shipping. Rules for Building and Classing Steel Vessel Rules Part 2, Rules for Materials and Welding. Houston: ABS; 2013. p. 40-44. Chapter 1: Materials for Hull Construction, Section 5 Hull Steel Casting.

[76] Bureau Veritas. Rules on Materials and Welding for the Classification of Marine Units. Rule Note NR 216 DT R05 E-Materials Steel and Welding. Paris: Bureau Veritas; 2011. p. 92-105. Chapter 2: Steel and Iron Products, Section 4 Steel Castings.

[77] Det Norske Veritas AS. Offshore Standard DNV-OS-B101 Metallic Materials. Høvik: DNV-GL; 2012. p. 41-48. Section 4: Steel Castings.

[78] Leng S, Miao Z, Sun P, Yao X. Study on CTOD and microstructure in flash welded joints for 630-730 MPa grade mooring chains. In: Proceedings of the 13th International Conference of Fracture; 2013 June 16-21; Beijing, China. Beijing: The Chinese Society of Theoretical and Applied Mechanics. p. 1-10.

[79] Arredondo A, Férnandez J, Silveira E, Arana JL. Corrosion fatigue behavior of mooring chain steel in seawater, In: Proceedings of the 35th International Conference on Ocean, Offshore and Arctic Engineering; 2016; Busan, Korea. Busan: ASME; 2016. p. 1-8. http://dx.doi.org/10.1115/OMAE2016-54426.

[80] Idapalapati S, Akisanya AR, Loh KKM, Yeo S. Failure analysis of a failed anchor chain link. Engineering Failure Analysis, 2018;89(6):258270. http://dx.doi.org/10.1016/j.engfailanal.2018.03.007.

[81] Chen J, Li C, Jin X, Chen L, Fang L. Effect of quenching process on microstructures and mechanical properties of Fe- $0.9 \mathrm{Mn}$ $0.5 \mathrm{Cr}-2.4 \mathrm{Ni}-0.5 \mathrm{Mo}-\mathrm{C}$ steel. Journal of Materials Engineering and Performance. 2018;27(4):1505-1513. http://dx.doi.org/10.1007/ s11665-018-3163-7.

[82] Kim I, Lee M, Choi Y, Kang N. Effects of Mo content on low-angle misorientation microstructure and mechanical properties of YS $550 \mathrm{MPa}$-grade steels for offshore structures. Steel Research International. 2017;89(2):1-6. http://dx.doi.org/10.1002/ srin. 201700278.

[83] Wang Q, Li C, Peng H, Chen J, Zhang J. Effect of tempering temperature on the microstructureand properties of $\mathrm{Fe}-2 \mathrm{Cr}-\mathrm{Mo}$ $0.12 \mathrm{C}$ pressure vessel steel. Journal of Materials Engineering and Performance. 2018;27(4):1485-1493. http://dx.doi.org/10.1007/ s11665-017-2856-7.

[84] Li Q, Huang X, Huang W. EBSD analysis of relationship between microstructural features and toughness of a medium-carbon quenching and partitioning bainitic steel. Journal of Materials Engineering and Performance. 2017;26(12):6149-6157. http:// dx.doi.org/10.1007/s11665-017-3052-5. 